Supplement of Hydrol. Earth Syst. Sci., 22, 1193-1219, 2018

https://doi.org/10.5194/hess-22-1193-2018-supplement

(C) Author(s) 2018. This work is distributed under

the Creative Commons Attribution 3.0 License.

(c) (1)

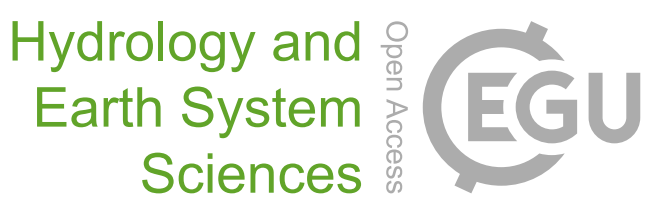

Supplement of

\title{
Parametric soil water retention models: a critical evaluation of expressions for the full moisture range
}

Raneem Madi et al.

Correspondence to: Gerrit Huibert de Rooij (gerrit.derooij@ufz.de)

The copyright of individual parts of the supplement might differ from the CC BY 3.0 License. 


\section{S1. Soil water retention and hydraulic conductivity functions}

This section reviews the most popular parameterizations of the soil water retention curve and several lesserknown others that were developed to improve the fit in the dry range or at least eliminate the need for the physically poorly defined residual water content. At this time, we consider unimodal functions only. The physical plausibility in terms of the rate of change near saturation of the corresponding conductivity models is verified, thereby maintaining the consistency between the retention and the conductivity curves that would have been lost in Iden et al.'s (2015) approach. In all cases but one, this physical plausibility is checked for the first time. The plausibility check requires that the derivative of each retention curve is determined and the criterion in Eq. (4) of the is used to define the permissible range for $\kappa$. If this range does not include any of the values $\{1,2\}$ used by the conductivity models described above, or if the permitted values are non-physical $(<0)$, the retention model does not have a conductivity model associated with it, which limits its practical value. As above, $h$ denotes the matric potential, which is negative in unsaturated soils. Many of the cited papers adopt this notation for its opposite, the suction.

$\theta(h)= \begin{cases}\theta_{r}+\left(\theta_{s}-\theta_{r}\right)\left(\frac{h}{h_{a e}}\right)^{-\lambda}, & h \leq h_{a e} \\ \theta_{s}, & h>h_{a e}\end{cases}$

This equation is referred to as BCO below. The derivative is

20

$$
\frac{\mathrm{d} \theta}{\mathrm{d} h}= \begin{cases}\frac{-\lambda\left(\theta_{s}-\theta_{r}\right)}{h_{a e}}\left(\frac{h}{h_{a e}}\right)^{-\lambda-1}, & h \leq h_{a e} \\ 0, & h>h_{a e}\end{cases}
$$

where $\lambda$ is a dimensionless fitting parameter. If $\theta_{r}$ is set to zero, Campbell's (1974) equation is obtained.

The analytical expression for the generalized $K(h)$ function (Eq. (3)) for the water retention function of Brooks and Corey (1964) is 


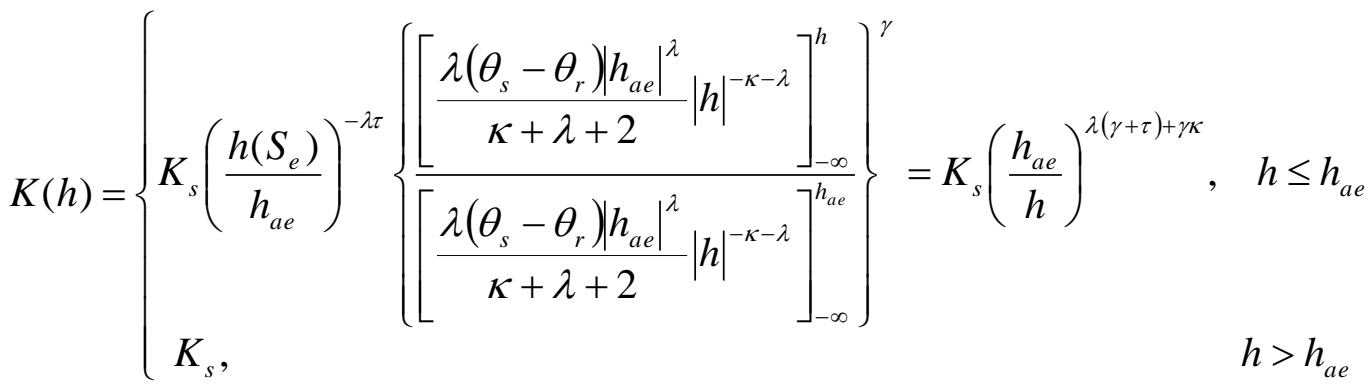

Note that the Brooks-Corey retention curve allows all three parameters of the associated conductivity model to be fitted.

The derivative of the Brooks-Corey function is discontinuous at $h_{a e}$. Hutson and Cass (1987) added a parabolic approximation at the wet end to make the first derivative continuous. For $\theta_{r}=0$, they proposed

$$
\begin{cases}\theta_{s}\left(\frac{h}{h_{a e}}\right)^{-\lambda}, & h \leq h_{i} \\ \theta_{s}\left[1-\left(\frac{h}{h_{a e}}\right)^{2} \frac{\left(1-\frac{2}{\lambda+2}\right)}{\left.\left(\frac{2}{\lambda+2}\right)^{-\frac{2}{\lambda}}\right]}\right] & 0 \geq h>h_{i}\end{cases}
$$

35

where $h_{i}[\mathrm{~L}]$ is the matric potential at the inflection point, given by:

$$
h_{i}=h_{a e}\left(\frac{2}{2-\lambda}\right)^{\frac{1}{\lambda}} \text {. }
$$

$$
\frac{\mathrm{d} \theta}{\mathrm{d} h}=\left\{\begin{array}{lr}
-\frac{\lambda \theta_{s}}{h_{a e}}\left(\frac{h}{h_{a e}}\right)^{-\lambda-1}, & h \leq h_{i} \\
\frac{2 \theta_{s}}{h_{a e}} \frac{\left(\frac{2}{\lambda+2}-1\right)}{\left(\frac{2}{\lambda+2}\right)^{-\frac{2}{\lambda}}}\left(\frac{h}{h_{a e}}\right), & 0 \geq h>h_{i}
\end{array}\right.
$$


The parameter $h_{a e}$ no longer is an air-entry value and should be considered a pure fitting parameter. It should be noted that the smooth transition to saturation that this function and several others mimic may at least in part be caused by the non-zero height of the soil cores used in experiments to determine soil water retention curves. At hydrostatic equilibrium, the matric potential along the vertical varies in the soil core, resulting in a differentiable shape of the apparent soil water retention curve, even if the soil in the core has a uniform air-entry value that leads to a locally non-differentiable curve (Liu and Dane, 1995).

The parabolic approximation of Hutson and Cass (1987) leads to the following expression for the term in Eq. (4)

$\lim _{h \rightarrow 0} A_{1}|h|^{1-\kappa}=0$

where $A_{1}$ is a constant. This leads to the requirement that $\kappa<1$, ruling out the usual models. Although the parabolic approximation in itself does not preclude the existence of a closed-form expression for $K$, the restriction on $\kappa$ is quite severe, so we do not pursue this further.

Van Genuchten's (1980) formulation is also continuously differentiable:

$60 \quad \theta(h)=\theta_{r}+\left(\theta_{s}-\theta_{r}\right)\left(1+|\alpha h|^{n}\right)^{-m}, \quad h \leq 0$

where $\alpha\left[\mathrm{L}^{-1}\right], n$, and $m$ are shape parameters. This equation is denoted by VGN below. It has the derivative

$$
\frac{\mathrm{d} \theta}{\mathrm{d} h}=\alpha m n\left(\theta_{s}-\theta_{r}\right)|\alpha h|^{n-1}\left(1+|\alpha h|^{n}\right)^{-m-1}, \quad h \leq 0
$$

where often $m$ is set equal to $1-1 / n$.

The limit of the derivative of van Genuchten's (1980) retention curve near saturation is

$\left.\frac{\mathrm{d} \theta}{\mathrm{d} h}\right|_{h=0}=\alpha^{n} \operatorname{mn}\left(\theta_{s}-\theta_{r}\right)|h|^{n-1}$

leading to the requirement that $\kappa<n-1$. For many fine and/or poorly sorted soil textures, $n$ ranges between 1 and 2. Therefore, this restriction can be even more severe than the one required for a parabolic wet end, even excluding Mualem's (1976) conductivity model when $n<2$. For this reason we refrain from formulating analytical conductivity equations, even though van Genuchten (1980) presented such expressions for Burdine's (1953) and Mualem's (1976) models. 
Vogel et al. (2001) presented a modification to improve the description of the hydraulic conductivity near saturation without being aware of the physical explanation of the poor behavior presented later by Ippisch et al. (2006). Their retention function reads

$\theta(h)= \begin{cases}\theta_{r}+\left(\theta_{m}-\theta_{r}\right)\left(1+|\alpha h|^{n}\right)^{-m}, & h<h_{s} \\ \theta_{s}, & h \geq h_{s}\end{cases}$

where $h_{s}[\mathrm{~L}]$ is a fitting parameter close to zero with which $\theta_{m}$ can be defined as

$\theta_{m}=\theta_{r}+\left(\theta_{s}-\theta_{r}\right)\left(1+\left|\alpha h_{s}\right|^{n}\right)^{-m}$

85

The derivative is

$\frac{\mathrm{d} \theta}{\mathrm{d} h}= \begin{cases}\alpha m n\left(\theta_{m}-\theta_{r}\right)|\alpha h|^{n-1}\left(1+|\alpha h|^{n}\right)^{-m-1}, & h<h_{s} \\ 0, & h \geq h_{s}\end{cases}$

90 Schaap and van Genuchten (2006) reported a value of $h_{s}$ of $-4 \mathrm{~cm}$ to work best for a wide range of soils to improve the description of the near-saturated hydraulic conductivity. The parameter $h_{s}$ should therefore not be viewed as an air-entry value.

Although an expression can be derived for $K(h)$ if $\kappa$ is set to 1 and $m=1-1 / n$, we prefer to adopt the formulation by Ippisch et al. (2006), given its solid physical footing. They proposed to introduce an air-entry value and scale the unsaturated portion of the retention curve by its value at the water-entry value:

$\theta(h)= \begin{cases}\theta_{r}+\left(\theta_{s}-\theta_{r}\right)\left(\frac{1+|\alpha h|^{n}}{1+\left|\alpha h_{a e}\right|^{n}}\right)^{-m}, & h<h_{a e} \\ \theta_{s}, & h \geq h_{a e}\end{cases}$

with derivative

100

$\frac{\mathrm{d} \theta}{\mathrm{d} h}= \begin{cases}\alpha m n\left(\theta_{s}-\theta_{r}\right)|\alpha h|^{n-1}\left(1+\left|\alpha h_{a e}\right|^{n}\right)^{n}\left(1+|\alpha h|^{n}\right)^{-m-1}, & h<h_{a e} \\ 0, & h \geq h_{a e}\end{cases}$ 
With the common restriction of $m=1-1 / n$, an expression can be found for $\kappa=1$ that is slightly more general than Eq. (11) in Ippisch et al. (2006):

105

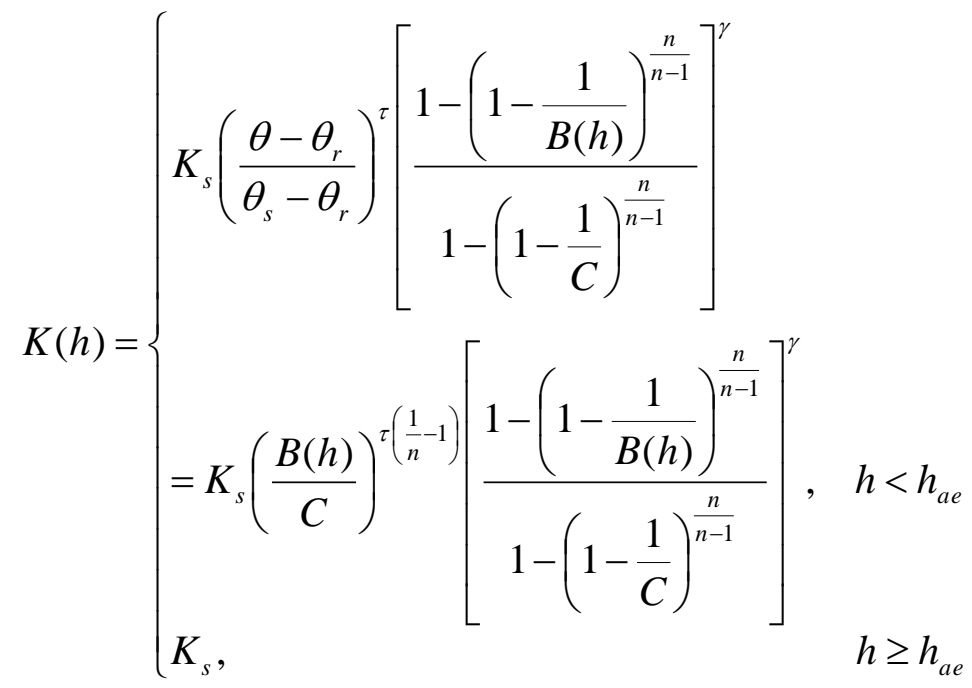

where

$B(h)=1+|\alpha h|^{n}$

110

$C=1+\left|\alpha h_{a e}\right|^{n}$

This equation can be used to define conductivity models according to Mualem (1976) and Alexander and Skaggs (1986), which both require that $\kappa=1$.

None of the retention models discussed so far performs very well in the dry range. Campbell and Shiozawa (1992) introduced a logarithmic section in the dry end to improve the fit in the dry range:

$\theta(h)=\theta_{a}\left(1-\frac{\ln |h|}{\ln \left|h_{d}\right|}\right)+A_{2}\left(\frac{1}{1+|\alpha h|^{4}}\right)^{m}$

with derivative

$\frac{\mathrm{d} \theta}{\mathrm{d} h}=\frac{\theta_{a}}{\ln \left|h_{d}\right|} \frac{1}{h}+4 \alpha m A_{2}|\alpha h|^{3}\left(1+|\alpha h|^{4}\right)^{-m-1}$ 
where $\theta_{a}$ represents the maximum amount of adsorbed water, $A_{2}$ is a constant and $h_{d}$ is the matric potential at ovendryness, below which the water content is assumed to be zero. The first term in the derivative leads to the requirement that $\kappa<-1$, and therefore no conductivity model can be derived from Eq. (S8a).

Rossi and Nimmo (1994) also preferred a logarithmic function over the Brooks-Corey power law at the dry end to better represent the adsorption processes that dominates water retention in dry soils, as opposed to capillary processes in wetter soils. They also implemented a parabolic shape at the wet end as proposed by Hutson and Cass (1987). Rossi and Nimmo (1994) presented two retention models, but only one (the junction model) permitted an analytical expression of the unsaturated hydraulic conductivity. Here, the junction model is presented with and without the parabolic expression for the wet end of the retention curve. With the discontinuous derivative at the airentry value, the expression reads

135

$\theta(h)=\left\{\begin{array}{lr}0, & h \leq h_{d} \\ \theta_{s} \beta \ln \left(\frac{h_{d}}{h}\right), & h_{d}<h \leq h_{j} \\ \theta_{s}\left(\frac{h_{a e}}{h}\right)^{\lambda}, & h_{j}<h \leq h_{a e} \\ \theta_{s}, & h>h_{a e},\end{array}\right.$

which is denoted RNA below. The derivative is

$$
\frac{\mathrm{d} \theta}{\mathrm{d} h}=\left\{\begin{array}{lr}
0, & h \leq h_{d} \\
\frac{\theta_{s} \beta}{-h}, & h_{d}<h \leq h_{j} \\
\lambda \theta_{s}\left|h_{a e}\right|^{\lambda}|h|^{-\lambda-1}, & h_{j}<h \leq h_{a e} \\
0, & h>h_{a e}
\end{array}\right.
$$

Rossi and Nimmo (1994) required the power law and logarithmic branches as well as their first derivatives to be equal at the junction point $\left(\theta_{j}, h_{j}\right)$. With $h_{d}$ fixed (Rossi and Nimmo found a value of $-10^{5} \mathrm{~m}$ for six out of seven soils and $-5 \cdot 10^{5} \mathrm{~m}$ for the seventh), these constraints allow two of the five remaining free parameters to be expressed in terms of the other three. Some manipulation leads to the expressions:

145

$$
\begin{aligned}
& \lambda=\frac{1}{\ln \left|h_{d}\right|-\ln \left|h_{j}\right|} \\
& \beta=\lambda\left(\frac{h_{a e}}{h_{j}}\right)^{\lambda}
\end{aligned}
$$


but other choices are possible. This choice leads to fitting parameters $h_{a e}, h_{j}$, and $\theta_{s}$. The associated conductivity model is

$$
\begin{aligned}
& \int 0, \quad h \leq h_{d} \\
& K_{s} S_{e}^{\tau}\left\{\frac{\left[-\frac{\theta_{s} \beta}{\kappa}|h|^{-\kappa}\right]_{h_{d}}^{h}}{\left[-\frac{\theta_{s} \beta}{\kappa}|h|^{-\kappa}\right]_{h_{d}}^{h_{j}}-\left[\frac{\theta_{s} \lambda}{\lambda+\kappa}\left|h_{a e}\right|^{\lambda}|h|^{-(\lambda+\kappa)}\right]_{h_{j}}^{h_{a e}}}\right\}^{\gamma} \\
& K(h)=\left\{\begin{array}{l}
=K_{s}\left[\beta \ln \left(\frac{h_{d}}{h}\right)\right]^{\tau}\left[\frac{E(h)}{E\left(h_{j}\right)+F\left(\left|h_{j}\right|^{-\lambda-\kappa}-\left|h_{a e}\right|^{-\lambda-\kappa}\right)}\right]^{\gamma}, \quad h_{d}<h \leq h_{j} \\
K_{s} S_{e}^{\tau}\left\{\frac{\left[-\frac{\theta_{s} \beta}{\kappa}|h|^{-\kappa}\right]_{h_{d}}^{h_{j}}-\left[\frac{\theta_{s} \lambda}{\lambda+\kappa}\left|h_{a e}\right|^{\lambda}|h|^{-(\lambda+\kappa)}\right]_{h_{j}}^{h}}{\left[-\frac{\theta_{s} \beta}{\kappa}|h|^{-\kappa}\right]_{h_{d}}^{h_{j}}-\left[\frac{\theta_{s} \lambda}{\lambda+\kappa}\left|h_{a e}\right|^{\lambda}|h|^{-(\lambda+\kappa)}\right]_{h_{j}}^{h_{a e}}}\right]^{\gamma}
\end{array}\right.
\end{aligned}
$$

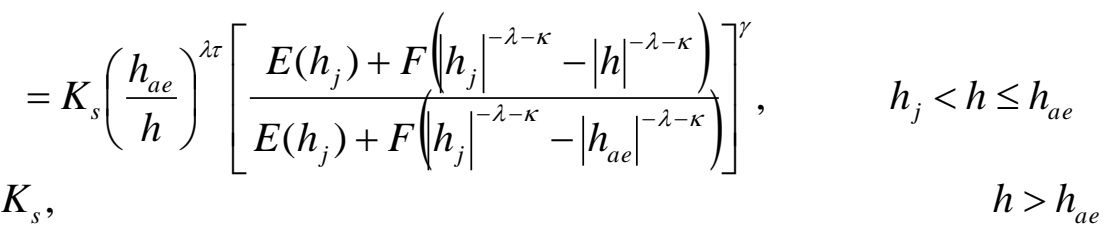

where

$E(h)=\frac{\beta}{\kappa}\left(\left|h_{d}\right|^{-\kappa}-|h|^{-\kappa}\right)$

$F=\frac{\lambda}{\lambda+\kappa}\left|h_{a e}\right|^{\lambda}$

It is worth noting that recent studies that considered the conductivity of water films in relatively dry soils show a reduction in the rate at which the $\log (K)$ dropped with increasing $\log (-h)$. This implies that requiring continuity of the first derivative at the junction where $h=h_{j}$ could be too strict (e.g. Tuller and Or (2001) and Assouline and Or (2013)).

The junction model of Rossi and Nimmo (1994) with a continuous first-order derivative achieved through the correction by Hutson and Cass (1987) reads 
$\theta(h)=\left\{\begin{array}{lc}0, & h \leq h_{d} \\ \theta_{s} \zeta_{1} \ln \left(\frac{h_{d}}{h}\right), & h_{d}<h \leq h_{j} \\ \theta_{s}\left(\frac{h_{a e}}{h}\right)^{\lambda}, & h_{j}<h \leq h_{i} \\ \theta_{s}\left[1-c_{1}\left(\frac{h}{h_{c}}\right)^{2}\right], & h_{i} \leq h \leq 0\end{array}\right.$

with the derivative

$\frac{\mathrm{d} \theta}{\mathrm{d} h}=\left\{\begin{array}{lr}0, & h \leq h_{d} \\ \frac{\theta_{s} \zeta_{1}}{-h}, & h_{d}<h \leq h_{j} \\ \lambda \theta_{s}\left|h_{a e}\right|^{\lambda}|h|^{-\lambda-1}, & h_{j}<h \leq h_{i} \\ \frac{-2 c_{1} \theta_{s}}{h_{c}^{2}} h, & h_{i} \leq h \leq 0\end{array}\right.$

$(\mathrm{S} 10 \mathrm{~b})$

where

$h_{i}=h_{c}\left(\frac{\lambda}{2}+1\right)^{\frac{1}{\lambda}}$

$(\mathrm{S} 10 \mathrm{c})$

$h_{j}=h_{d} \mathrm{e}^{-\frac{1}{\lambda}}$

$c_{1}=\frac{\lambda}{2}\left(\frac{2}{\lambda+2}\right)^{\frac{\lambda+2}{\lambda}}$

$\zeta_{1}=\mathrm{e} \lambda\left(\frac{h_{c}}{h_{d}}\right)^{\lambda}$

180 where $h_{c}[\mathrm{~L}]$ is a fitting parameter, together with $\lambda$ and $\theta_{s}$. The parabolic wet end restricts $\kappa$ to values between 0 and 1. For this reason, an expression for the conductivity curve is not derived.

Rossi and Nimmo (1994) also introduced an equation that summed up the power law and logarithmic contributions (the sum model): 


$$
\theta(h)=\left\{\begin{array}{lr}
0, & h \leq h_{d} \\
\theta_{s}\left[\left(\frac{h_{c}}{h}\right)^{\lambda}-\left(\frac{h_{c}}{h_{d}}\right)^{\lambda}+\zeta_{2} \ln \left(\frac{h_{d}}{h}\right)\right], & h_{d} \leq h \leq h_{i} \\
\theta_{s}\left[1-c_{2}\left(\frac{h}{h_{c}}\right)^{2}\right], & h_{i} \leq h \leq 0
\end{array}\right.
$$

with derivative

$$
\frac{\mathrm{d} \theta}{\mathrm{d} h}=\left\{\begin{array}{lc}
0, & h \leq h_{d} \\
-\frac{\theta_{s}}{h}\left[\lambda\left(\frac{h_{c}}{h}\right)^{\lambda}+\zeta_{2}\right], & h_{d} \leq h \leq h_{i} \\
\frac{-2 c_{2} \theta_{s}}{h_{c}^{2}} h, & h_{i} \leq h \leq 0
\end{array}\right.
$$

190

in which we have

$$
\zeta_{2}=\left[1-\left(\frac{\lambda}{2}+1\right)\left(\frac{h_{c}}{h_{i}}\right)^{\lambda}+\left(\frac{h_{c}}{h_{d}}\right)^{\lambda}\right]\left[\frac{1}{2}+\ln \left(\frac{h_{d}}{h_{i}}\right)\right]^{-1}
$$

195 and

$$
c_{2}=\left(\frac{h_{c}}{h_{i}}\right)^{2}\left[1-\left(\frac{h_{c}}{h_{i}}\right)^{\lambda}+\left(\frac{h_{c}}{h_{d}}\right)^{\lambda}-\frac{1-\left(\frac{\lambda}{2}+1\right)\left(\frac{h_{c}}{h_{i}}\right)^{\lambda}+\left(\frac{h_{c}}{h_{d}}\right)^{\lambda}}{\frac{1}{2 \ln \left(\frac{h_{d}}{h_{i}}\right)^{2}}+1}\right]
$$

A closed-form expression for the hydraulic conductivity does not exist for this function, and the permitted values for $\kappa$ are not physically acceptable.

Fayer and Simmons (1995) used the approach of Campbell and Shiozawa (1992) to have separate terms for adsorbed and capillary bound water. If the capillary binding is represented by a Brooks-Corey type function, the retention model becomes 


$$
\theta(h)=\left\{\begin{array}{lr}
0, & h \leq h_{d} \\
\theta_{a}\left(1-\frac{\ln |h|}{\ln \left|h_{d}\right|}\right)+\left[\theta_{s}-\theta_{a}\left(1-\frac{\ln |h|}{\ln \left|h_{d}\right|}\right)\right]\left(\frac{h_{a e}}{h}\right)^{\lambda}, & h_{d}<h<h_{a e} \\
\theta_{s}, & h \geq h_{a e}
\end{array}\right.
$$

205

This expression is denoted FSB below. The derivative is

$$
\frac{\mathrm{d} \theta}{\mathrm{d} h}=\left\{\begin{array}{lr}
0, & h \leq h_{d} \\
\frac{1}{|h|}\left(\frac{h_{a e}}{h}\right)^{\lambda}\left[\lambda\left(\theta_{s}-\theta_{a}\right)+\theta_{a}\left(\frac{\ln |h|}{\ln \left|h_{d}\right|}-\frac{1}{\ln \left|h_{d}\right|}\right)\right], & h_{d}<h<h_{a e} \\
0, & h \geq h_{a e}
\end{array}\right.
$$

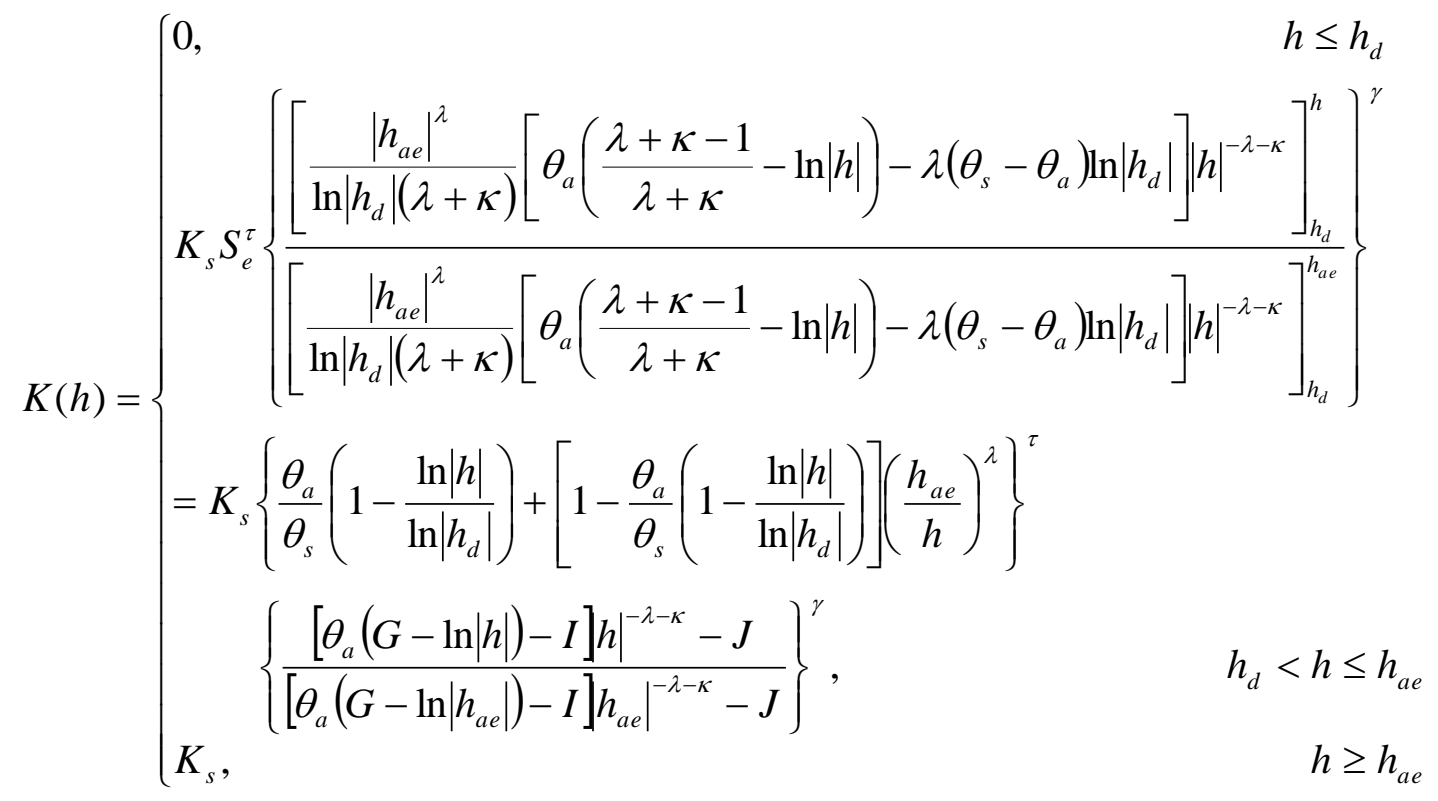

where

$$
G=\frac{\lambda+\kappa-1}{\lambda+\kappa}
$$


$I=\lambda\left(\theta_{s}-\theta_{a}\right) \ln \left|h_{d}\right|$

$J=\left.\left[\theta_{a}\left(G-\ln \left|h_{d}\right|\right)-I\right] h_{d}\right|^{-\lambda-\kappa}$

Note that the above model is valid if $h_{a e}$ does not exceed $-1 \mathrm{~cm}$. This condition will usually be met, unless the soil texture is very coarse.

If capillary binding is described by a van Genuchten function, the resulting equation is

225

$\theta(h)= \begin{cases}0, & h \leq h_{d} \\ \theta_{a}\left[1-\frac{\ln |h|}{\ln \left|h_{d}\right|}\right]+\left\{\theta_{s}-\theta_{a}\left[1-\frac{\ln |h|}{\ln \left|h_{d}\right|}\right]\right\}\left[1+(-\alpha h)^{n}\right]^{\frac{1}{n}-1}, & h_{d}<h<0\end{cases}$

with derivative

$\frac{\mathrm{d} \theta}{\mathrm{d} h}= \begin{cases}0, & h \leq h_{d} \\ \frac{\theta_{a}}{h \ln \left|h_{d}\right|}\left\{\left[1+(-\alpha h)^{n}\right]^{\frac{1}{n}-1}-1\right\} & \\ +\alpha(1-n)(-\alpha h)^{n-1}\left[1+(-\alpha h)^{n}\right]^{1-2}\left\{\theta_{a}\left[1-\frac{\ln |h|}{\ln \left|h_{d}\right|}\right]-\theta_{s}\right\}, & h_{d}<h<0\end{cases}$

The derivative has several terms that pose severe restrictions on the value of $\kappa$ (the first term even requires that $\kappa<$ -1 ), and other terms that limit the permitted values of $n$. The conductivity function is therefore omitted here.

In the original equations of both versions as presented by Fayer and Simmons (1995), the adsorbed water content reached zero at $h_{d}$, while there is still some capillary bound water at and below that matric potential, which is inconsistent. Furthermore, the terms with ratios of logarithms become negative for matric potentials below $h_{d}$. We therefore modified the original equations by setting the water content to zero below $h_{d}$.

Zhang (2011) presented a logarithmic extension of van Genuchten's (1980) model (Eq. (S4a)) in the dry end that is very similar to Eq. (S13a). The associated hydraulic conductivity model was the sum of Mualem's (1976) model and an expression for film flow conductivity. This approach only alleviated the issue of the residual water content but had the same problems near saturation as Eq. (S4a), and will therefore not be analyzed further.

Kosugi (1996) and Kosugi (1999) presented a soil water retention curve for soils with a lognormal pore size distribution. Khlosi et al. (2008) extended the approach of Campbell and Schiozawa (1992) and Fayer and Simmons (1995) to Kosugi's $(1996,1999)$ model. We again set the water content to zero for matric potentials below $h_{d}$ : 
$\theta(h)= \begin{cases}0, & h \leq h_{d} \\ \theta_{a}\left(1-\frac{\ln |h|}{\ln \left|h_{d}\right|}\right)+\left[\theta_{s}-\theta_{a}\left(1-\frac{\ln |h|}{\ln \left|h_{d}\right|}\right)\right] \frac{1}{2} \operatorname{erfc}\left[\frac{\ln \left(\frac{h}{h_{m}}\right)}{\sigma \sqrt{2}}\right], \quad h_{d}<h<0\end{cases}$

with the derivative (see Olver et al., 2010, p. 163 and p. 443)

$\frac{\mathrm{d} \theta}{\mathrm{d} h}=\left\{\frac{\theta_{a}}{h \ln \left|h_{d}\right|}\left\{\frac{1}{2} \operatorname{erfc}\left[\frac{\ln \left(\frac{h}{h_{m}}\right)}{\sigma \sqrt{2}}\right]-1\right\}+\frac{\theta_{a}\left(1-\frac{\ln |h|}{\ln \left|h_{d}\right|}\right)-\theta_{s}}{h \sigma \sqrt{2 \pi}} \exp \left\{-\left[\frac{\ln \left(\frac{h}{h_{m}}\right)}{\sigma \sqrt{2}}\right], \quad h_{d}<h<0\right.\right.$

Parameter $h_{m}[\mathrm{~L}]$ represents the matric potential corresponding to the median pore size, and $\sigma$ characterizes the width of the pore size distribution. The behavior of the derivative near saturation is not readily clear. Expressions for the corresponding hydraulic conductivity function can only be found for integer values of $\kappa$. For $\kappa=1$, the expression for the hydraulic conductivity is 


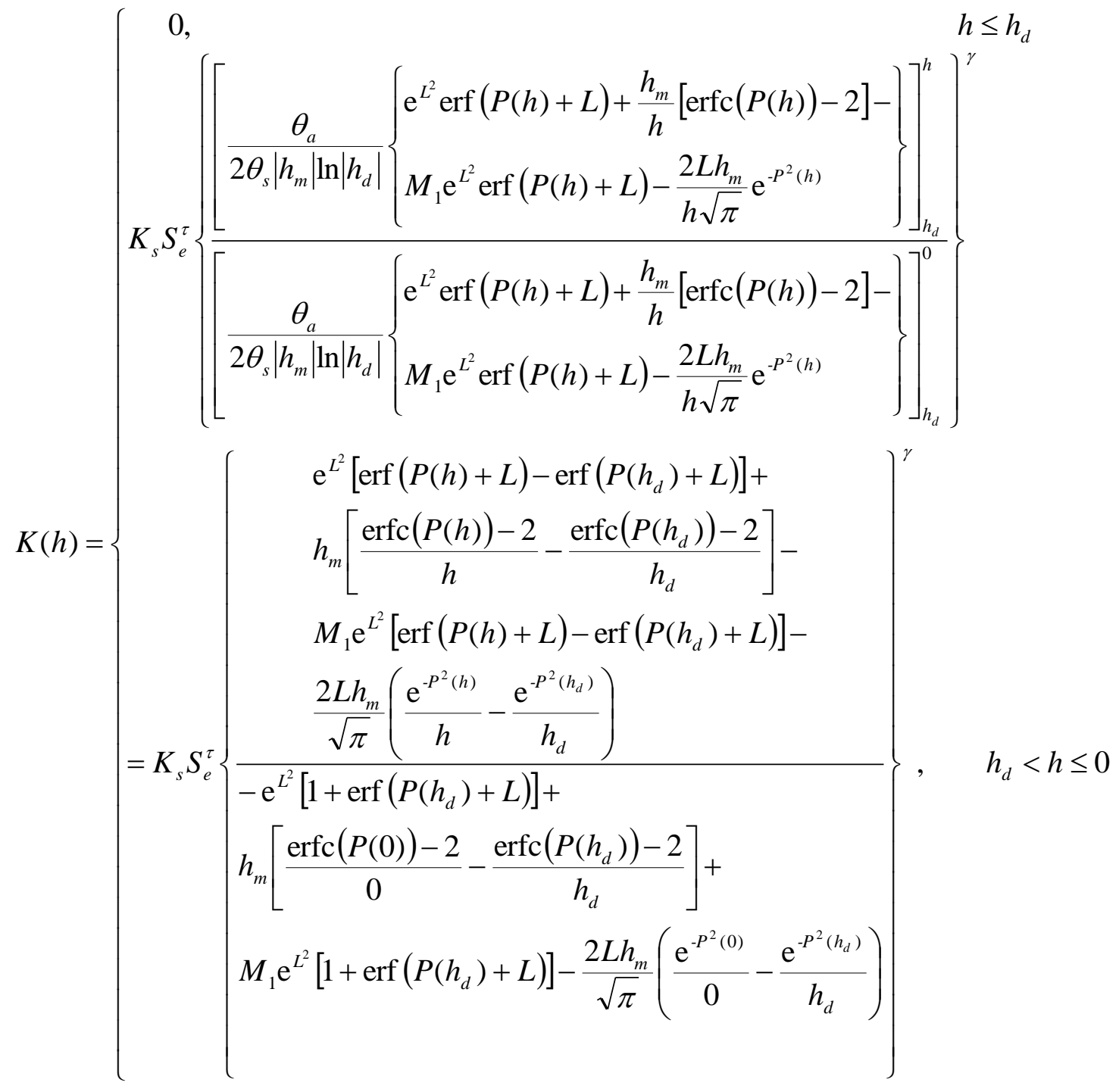

$(\mathrm{S} 14 \mathrm{c})$

where $S_{e}$ is obtained by dividing Eq. (S14a) by $\theta_{s}$. The following functions and derived variables have been used for clarity:

$L=\frac{\sigma \sqrt{2}}{2}$

$P(h)=\frac{\ln \left(\frac{h}{h_{m}}\right)}{\sigma \sqrt{2}}$

$(\mathrm{S} 14 \mathrm{e})$ 
For $\kappa=2$, the expression for the hydraulic conductivity reads:

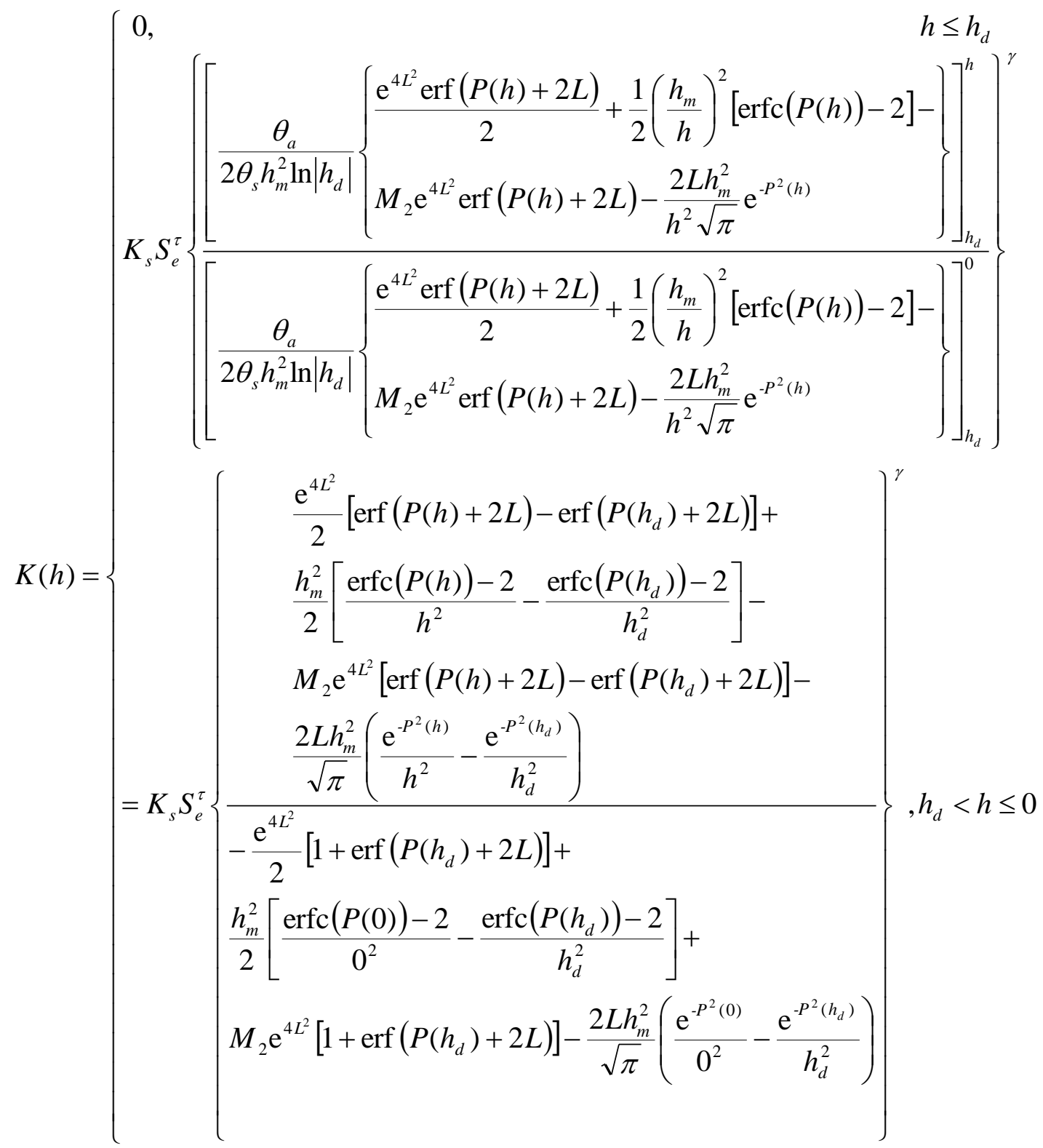

270 with

$$
M_{2}=\left(1-\frac{\theta_{s}}{\theta_{a}}\right) \ln \left|h_{d}\right|-\ln \left|h_{m}\right|+2 \sigma^{2}
$$


There are several terms with zero in the denominator in Eqs. (S14c) and (S14h). In these terms, the numerator is zero as well. The terms $\exp \left(P^{-2}(h)\right) \cdot h^{-1}$ and $\exp \left(P^{-2}(h)\right) \cdot h^{-2}$ appearing in Eqs. (S14c) and (S14h) both become infinite for all physically acceptable values of $h_{m}$ and $\sigma$. As a consequence, the unsaturated hydraulic conductivity for both values of $\kappa$ suffers from the non-realistic increase near saturation diagnosed by Ippisch et al. (2006) for van Genuchten's (1980) soil water retention model, and the use of Eqs. (S14c-h) is not recommended.

Groenevelt and Grant (2004) proposed:

$$
\theta(h)=\left\{\begin{array}{lr}
0, & h \leq-10^{6.9} \mathrm{~cm} \\
g_{1}\left\{\exp \left(\frac{-g_{0}}{6.9^{\eta}}\right)-\exp \left[\frac{-g_{0}}{\left(\log _{10} h \mid\right)^{\eta}}\right]\right\}, & -10^{6.9} \leq h \leq-1 \mathrm{~cm} \\
g_{1} \exp \left(\frac{-g_{0}}{6.9^{\eta}}\right), & h \geq-1 \mathrm{~cm}
\end{array}\right.
$$

where $g_{0}, g_{1}$, and $\eta$ are fitting parameters. The constant water content for matric potentials larger than $-1 \mathrm{~cm}$ is imposed. Groenevelt and Grant (2004) proposed a more flexible curve-shifting approach, but that procedure is cumbersome to perform in a global search parameter fitting operation. The derivative is

$$
\frac{\mathrm{d} \theta}{\mathrm{d} h}=\left\{\begin{array}{lr}
0, & h \leq-10^{6.9} \mathrm{~cm} \\
\frac{g_{0} g_{1} \eta[\ln (10)]^{\eta}}{|h|(\ln |h|)^{\eta+1}} \exp \left\{\frac{-g_{0}[\ln (10)]^{\eta}}{(\ln |h|)^{\eta}}\right\},-10^{6.9} \leq h \leq-1 \mathrm{~cm} \\
0, & h \geq-1 \mathrm{~cm}
\end{array}\right.
$$

This expression does not permit a closed-form expression for the hydraulic conductivity function.

Peters (2013) introduced four soil water retention models. He used a logarithmic model for adsorbed water that differed from that of Campbell and Shiozawa (1992) and the capillary model of either van Genuchten (1980) or Kosugi (1999). He developed versions for which the water content could be non-zero at the oven-dry matric potential $h_{d}$, which is incorrect but permits closed-from expressions of the hydraulic conductivity function. He also presented versions for which the water content is forced to be zero at $h_{d}$.

For the versions with nonzero water contents at $h_{d}$, the capillary bound and adsorbed water contents are added (Peters, 2013, Eq. (2))

$$
S_{e}(h)=w S^{c a p}(h)+(1-w) S^{a d}(h)
$$


where the superscripts cap and $a d$ reflect capillary bound and adsorbed water, respectively, and $w$ is a weighting factor ranging between 0 and 1 . The van Genuchten-version with non-zero water content at $h_{d}$ is

$$
\theta(h)= \begin{cases}\theta_{s} w\left[1+(-\alpha h)^{n}\right]^{\frac{1}{n}-1}+\theta_{s}(1-w) \frac{\ln \left(1+\frac{h}{h_{a}}\right)}{1-\frac{\ln \left(1+\frac{h_{d}}{h_{a}}\right)}{\ln (2)},} & \\ \theta_{s} w\left[1+\left(1+\frac{h_{d}}{h_{a}}\right)\right. & \\ \left.1-\alpha h)^{n}\right]^{\frac{1}{n}-1}+\theta_{s}(1-w), & 0 \geq h \geq h_{a}\end{cases}
$$

with derivative

$$
\frac{\mathrm{d} \theta}{\mathrm{d} h}= \begin{cases}-\theta_{s} w \alpha(1-n)(-\alpha h)^{n-1}\left[1+(-\alpha h)^{n}\right]^{\frac{1}{n}-2}+\frac{\theta_{s}(1-w)}{h+h_{a}} \frac{1}{\ln \left(1+\frac{h_{d}}{h_{a}}\right)-\ln (2)}, h \leq h_{a} \\ -\theta_{s} w \alpha(1-n)(-\alpha h)^{n-1}\left[1+(-\alpha h)^{n}\right]^{]^{-1}-2}, & 0 \geq h \geq h_{a}\end{cases}
$$

The parameter $h_{a}[\mathrm{~L}]$ represents the matric potential at which the soil reaches the maximum adsorbed water content.

The Kosugi-version with non-zero water content at air-dryness is

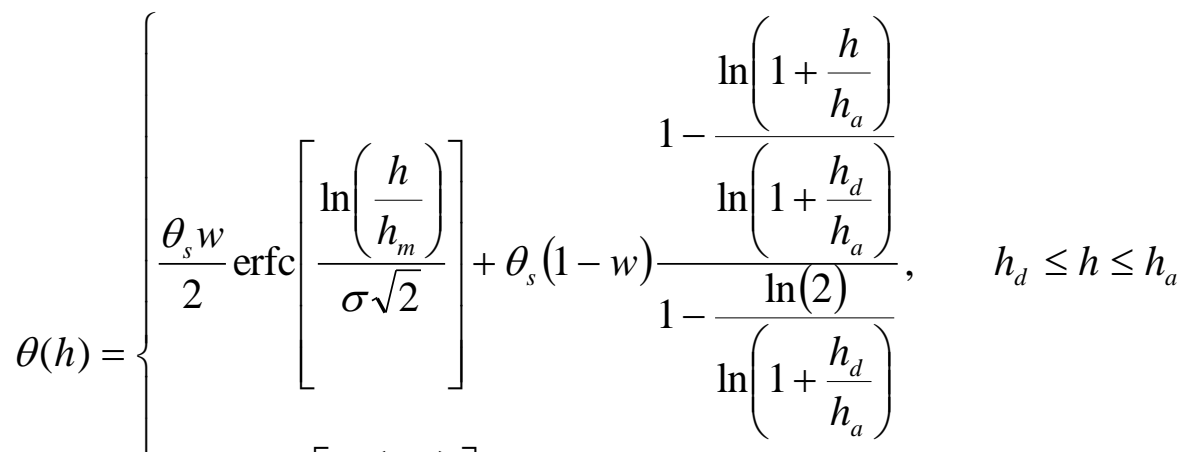

$$
\begin{aligned}
& \frac{\theta_{s} w}{2} \operatorname{erfc}\left[\frac{\ln \left(\frac{h}{h_{m}}\right)}{\sigma \sqrt{2}}\right]+\theta_{s}(1-w), \quad 0 \geq h \geq h_{a}
\end{aligned}
$$


with derivative

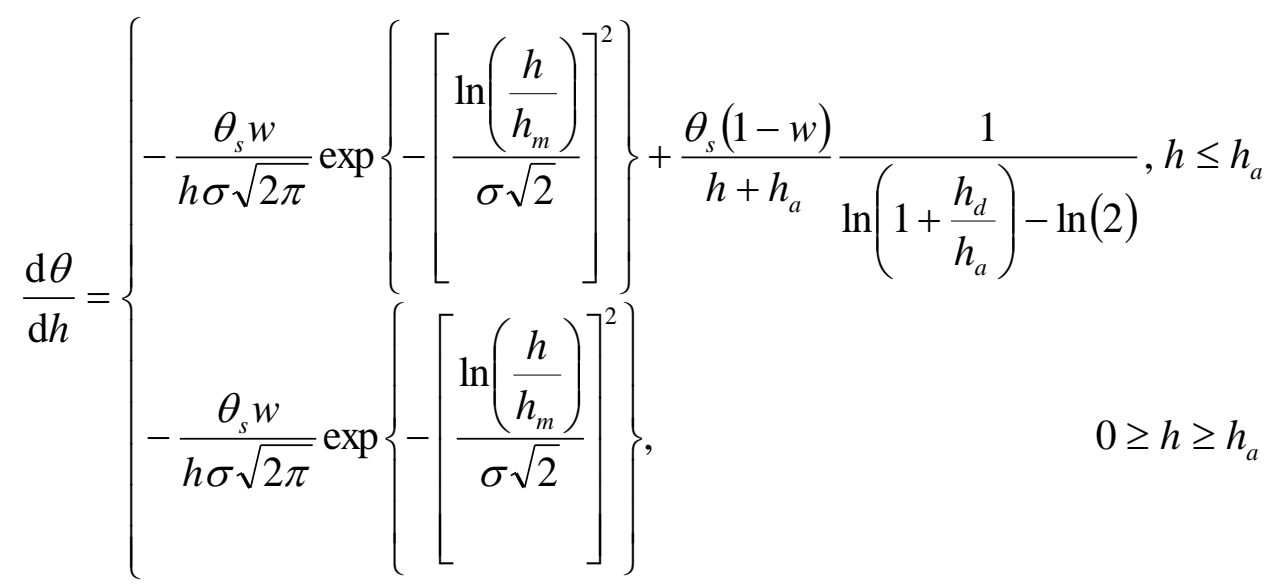

The van Genuchten-version with zero water content when the soil is air dry is

$$
\theta(h)= \begin{cases}0, & h \leq h_{d} \\ \theta_{s}\left(w\left\{\left[1+(-\alpha h)^{n}\right]^{\frac{1}{n}-1}-1\right\}+1\right) \frac{\ln \left(1+\frac{h}{h_{a}}\right)}{1-\frac{\ln \left(1+\frac{h_{d}}{h_{a}}\right)}{\ln (2)},} & \\ \theta_{s} w\left[1+(-\alpha h)^{n}\right]^{\frac{1}{n}-1}+\theta_{s}(1-w), & \\ h_{d} \leq h \leq h_{a}\end{cases}
$$




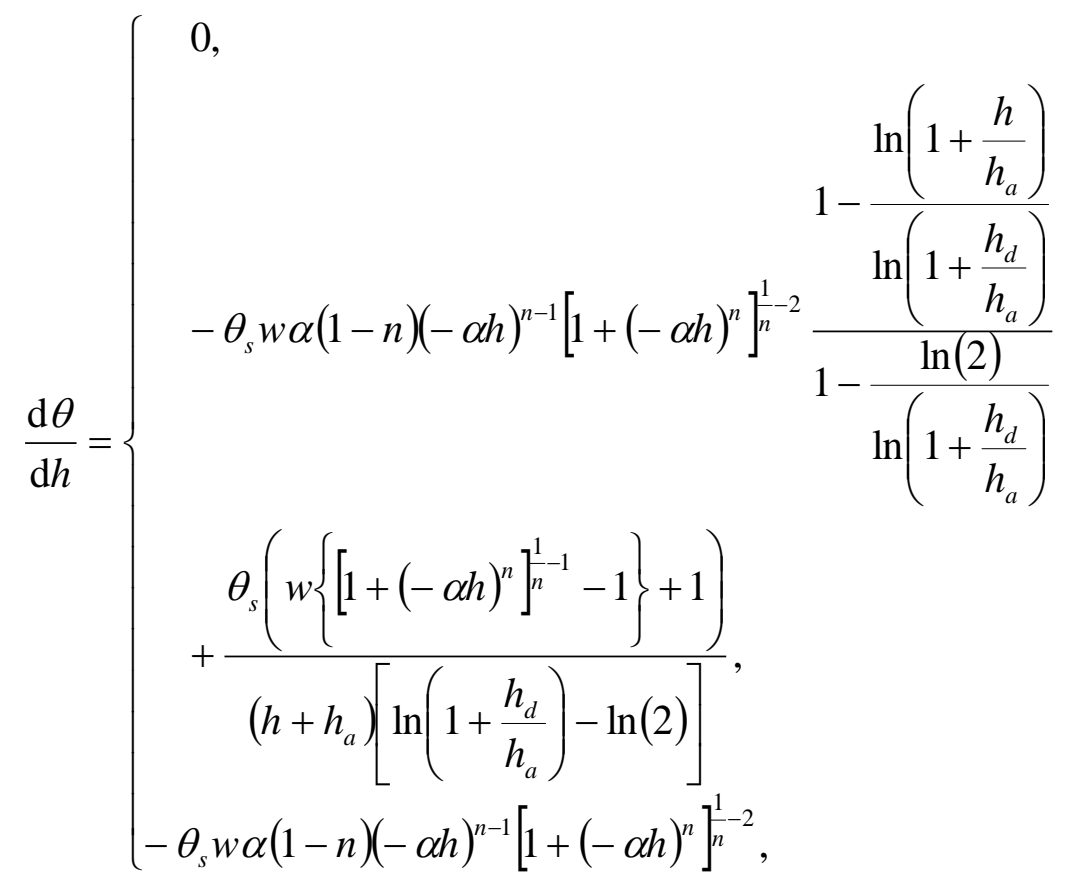

$$
h \leq h_{d}
$$

$0 \geq h \geq h_{a}$

(S19b)

The Kosugi-version with zero water content at $h_{d}$ is

325

$$
\theta(h)= \begin{cases}0, & h \leq h_{d} \\ \theta_{s}\left(w\left\{\frac{1}{2} \operatorname{erfc}\left[\frac{\ln \left(\frac{h}{h_{m}}\right)}{\sigma \sqrt{2}}\right]-1\right\}+1 \frac{\ln \left(1+\frac{h}{h_{a}}\right)}{1-\frac{\ln \left(1+\frac{h_{d}}{h_{a}}\right)}{\ln (2)},}\right. & h_{d} \leq h \leq h_{a} \\ \frac{\theta_{s} w}{2} \operatorname{erfc}\left[\frac{\ln \left(\frac{h}{h_{a}}\right)}{\sigma \sqrt{2}}\right]+\theta_{s}(1-w), & 0 \geq h \geq h_{a}\end{cases}
$$

with derivative 


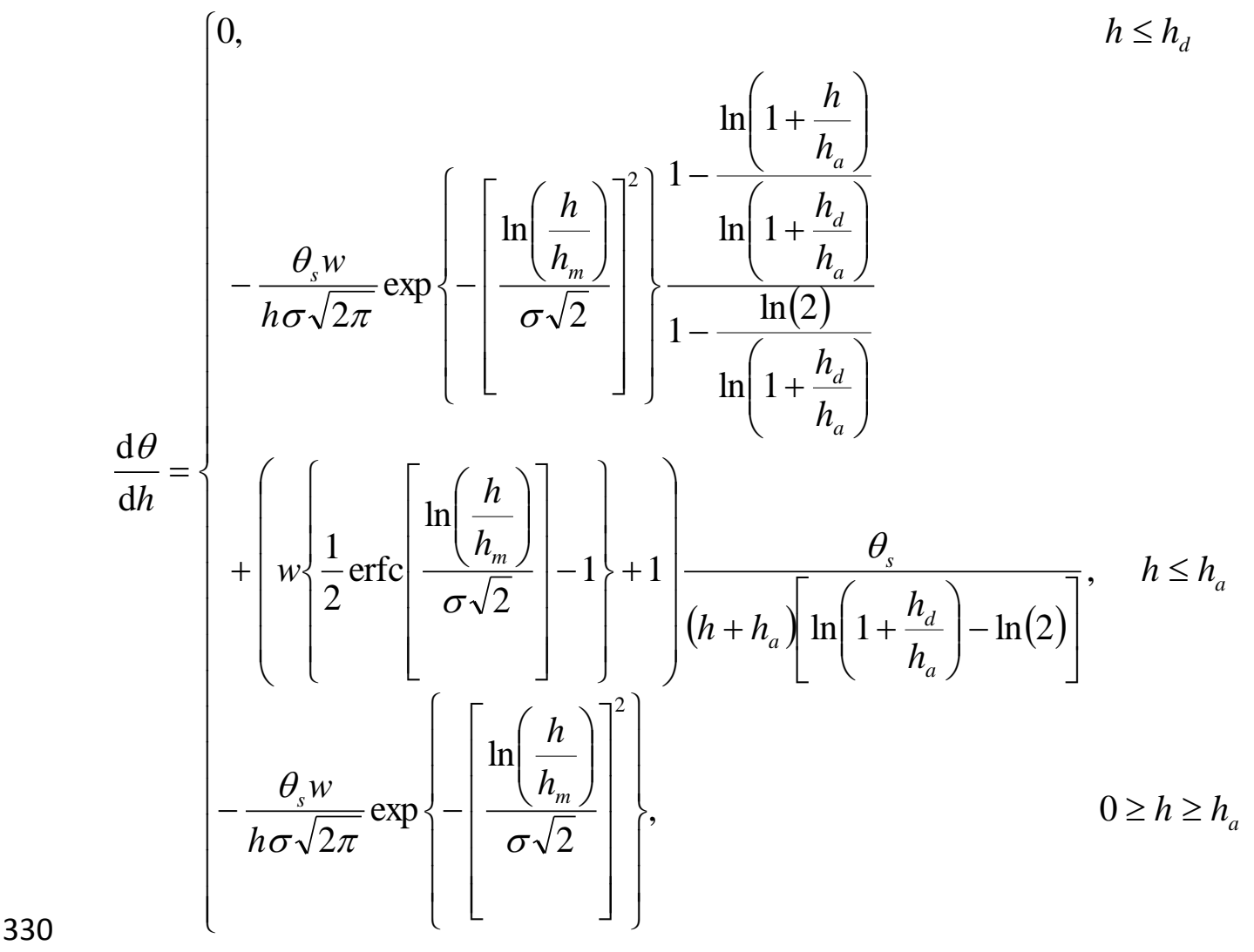

(S20b)

Both water retention functions based on van Genuchten's (1980) model (Eqs. (S17a) and (S19a)) lead to the requirement that $\kappa$ be smaller than $n-1$ (see Eq. (9)) and therefore do only have a physically acceptable conductivity curve associated with them for a very limited range of $\kappa$. The Kosugi-based versions (Eqs. (S18a) and (S20a)) suffer from the same lack of clarity about the behavior of the derivative as Khlosi et al.'s (2008) modified Kosugi function and require integer values of $\kappa$. Because of these limitations and the unwieldy nature of the equations (compare Eqs. (S14c-h)), their practical value seems limited.

Iden and Durner (2014) proposed modifications of Peters' (2013) models that permitted an analytical expression for the conductivity function even if the water content was forced to be zero at $h_{d}$. To apply the criterion of Eq. (4) to this modification, we multiply the derivative of their retention curve (their Eq. (3)) for adsorbed water by $h^{-\kappa}$ :

$$
\theta_{s}|h|^{-\kappa} \frac{\mathrm{d} S^{a d}}{\mathrm{~d} h}=\frac{\theta_{s}|h|^{-\kappa-1}}{\ln (10)\left(\log \left|h_{a}\right|-\log \left|h_{d}\right|\right)}\left[1-\frac{\exp \left(\frac{\log \left|h_{a}\right|-\log |h|}{b}\right)}{1+\exp \left(\frac{\log \left|h_{a}\right|-\log |h|}{b}\right)}\right]
$$


where $b$ is a shape parameter. High values of $b$ lead to a sharp transition between the two linear segments in the semi-logarithmic form of the adsorbed water retention curve with different slopes. Iden and Durner recommend values of $b$ between 0.1 and 0.3 .

In the limit as $h$ approaches zero, Eq. (S21) simplifies to

350

$\lim _{h \rightarrow 0}\left(\theta_{s} \mid h^{-\kappa} \frac{\mathrm{d} S^{a d}}{\mathrm{~d} h}\right)=\frac{\theta_{s}|h|^{-\kappa-1}}{\ln (10)\left(\log \left|h_{a}\right|-\log \left|h_{d}\right|\right)}\left[1-\frac{\exp \left(\frac{-\log |h|}{b}\right)}{1+\exp \left(\frac{-\log |h|}{b}\right)}\right]$

The approximation in the last term leads to the requirement that $\kappa<-1$ for the limit to go to zero for any value of $b$, but small values of $b$ allow larger ranges of $\kappa$. For $b=0.3$, trial calculations showed that the value in the limit appears to be zero for $\kappa<0.2$, which still rules out the established conductivity models. For $b=0.1$, the limit is zero even for large positive values of $\kappa$. It might be recommendable to fix $b$ at 0.1 instead of treating it as a fitting parameter.

The scaling of the capillary soil water retention curves proposed by Iden and Durner (2014) does not alleviate the problems with the van Genuchten curve near saturation while the Kosugi-function remains unwieldy. Conductivity functions for Peters' (2013) retention models will therefore not be derived.

Rudiyanto et al. (2015) developed a hysteretic version of Iden and Durner's (2014) model with the associated conductivity function. While of considerable interest, this model suffers from the same limitation as the original, and it will therefore not be further explored here.

In summary, many of the retention curves examined result in conductivity curves with physically unacceptable behavior near saturation, even though several of these expressions were derived with the explicit purpose of providing closed-form expressions for the hydraulic conductivity. Only the Brooks-Corey function (1964) (BCO, Eq. (S1a)), the junction model of Rossi and Nimmo (1994) without the parabolic correction (RNA, Eq. (S9a)), and the model of Fayer and Simmons (1995) based on the Brooks-Corey (1964) retention function(FSB, Eq. (S12a)) lead to an acceptable conductivity model with full flexibility (three free parameters: $\kappa, \gamma, \tau)$. The modified van Genuchten (1980) retention curve with a distinct air-entry value by Ippisch et al. (2006) (VGA, Eq. (S7a)) leads to a conductivity model with two fitting parameters if $m=1-1 / n$ because $\kappa=1$.

\section{References}

375 Alexander, L. and Skaggs, R. W.: Predicting unsaturated hydraulic conductivity from the soil water characteristic, Trans. Am. Soc. Agric. Eng., 29, 176-184, 1986. 
Brooks, R. H. and Corey, A. T.: Hydraulic properties of porous media, Colorado State Univ., Hydrology Paper No. 3, 27 pp, 1964.

Burdine, N. T.: Relative permeability calculations from pore size distribution data, Trans. Am. Inst. Min. Metall. Pet. Eng., 198, 71-81, 1953.

Campbell, G. S.: A simple method for determining unsaturated hydraulic conductivity from moisture retention data, Soil Sci., 117, 311-314, 1974.

Campbell, G. S., and Shiozawa, S.: Prediction of hydraulic properties of soils using particle-size distribution and bulk density data, In: van Genuchten, M. Th., Leij, F. J., and Lund, L. J. (eds.), Indirect methods for estimating the hydraulic properties of unsaturated soils. Univ. of California, Riverside, 317-328, 1992.

Fayer, M. J. and Simmons, C. S.: Modified soil water retention functions for all matric suctions, Water Resour. Res., 31, 1233-1238, 1995.

Groenevelt, P. H. and Grant, C. D.: A new model for the soil-water retention curve that solves the problem of residual water contents, European J. of Soil Science, 55, 479-485, doi: 10.1111/j.13652389.2004.00617.x, 2004.

Hutson, J. L. and Cass, A.: A retentively functions for use in soil-water simulation models, J. of Soil Sci., 38, 105$113,1987$.

Iden, S. C., and Durner, W.: Comment on 'Simple consistent models for water retention and hydraulic conductivity in the complete moisture range' by Peters, A. Water Resour. Res., 50, 7530-7534, doi: 10.1002/2014WR015937, 2014.

Iden, S. C., Peters, A., and Durner, W.: Improving prediction of hydraulic conductivity by constraining capillary bundle models to a maximum pore size, Adv. Water Resources, 85, 86-92, doi:10.1016/j.advwatres, 2015.09.005, 2015.

Ippisch, O., Vogel, H. -J., and Bastian, P.: Validity limits for the van Genuchten-Mualem model and implications for parameter estimation and numerical simulation, Adv. Water Resources, 29,1780-1789, doi:10.1016/j.advwatres.2005.12.011, 2006.

Khlosi, M., Cornelis, W. M., Douaik, A., van Genuchten, M. Th. and Gabriels, D.: Performance evaluation of models that describe the soil water retention curve between saturation and oven dryness, Vadose Zone J., 7, 87-96. doi:10.2136/vzj2007.0099, 2008.

405 Kosugi, K.: Lognormal distribution model for unsaturated soil hydraulic properties, Water Resour. Res., 32, 2697 2703, 1996.

Kosugi, K.: General model for unsaturated hydraulic conductivity for soils with lognormal pore-size distribution, Soil Sci. Soc. Am. J., 63, 270-277, 1999.

Liu, H. H., and Dane, J. H.: Improved computational procedure for retention relations of immiscible fluids using pressure cells, Soil Sci. Soc. Am. J., 59, 1520-1524, 1995.

Mualem, Y.: A new model for predicting the hydraulic conductivity of unsaturated porous media, Water Resour. Res., 12, 513-521, 1976. 
National Agricultural Library: https://data.nal.usda.gov/dataset/unsoda-20-unsaturated-soil-hydraulic-databasedatabase-and-program-indirect-methods-estimating-unsaturated-hydraulic-properties_134, last access 11 September, 2017.

Nemes, A., Schaap, M. G., Leij, F. J., and Wösten, J. H. M.: Description of the unsaturated soil hydraulic database UNSODA version 2.0, J. Hydrol., 251, 152-162, doi:10.1016/S0022-1694(01)00465-6, 2001.

Olver, F. W. J., Lozier, D. W., Boisvert, R. F., and Clark, C. W. (Editors): NIST Handbook of mathematical functions. National Institute of Standards and Technology (U.S. Dept. of Commerce), and Cambridge University Press, Cambridge, UK, 2010.

Peters, A.: Simple consistent models for water retention and hydraulic conductivity in the complete moisture range, Water Resour. Res., 49, 6765-6780, doi:10.1002/wrcr.20548, 2013.

Rossi, C., and Nimmo, J. R.: Modeling of soil water retention from saturation to oven dryness, Water Resour. Res., 30, 701-708, 1994.

Rudiyanto, Sakai, M., van Genuchten, M. Th., Alazba, A. A., Setiawan, B. I., and Minasny, B.: A complete soil hydraulic model accounting for capillary and adsorptive water retention, capillary and film conductivity, and hysteresis, Water Resour. Res., 51, 8757-8772, doi: 10.1002/2015WR017703, 2015.

Schaap, M. G., and van Genuchten, M. Th.: A modified Mualem-van Genuchten formulation for improved description of the hydraulic conductivity near saturation, Vadose Zone J., 5, 27-34, doi:10.2136/vzj2005.0005, 2006.

Tuller, M. and Or, D.: Hydraulic conductivity of variably saturated porous media: Film and corner flow in angular pore space. Water Resour. Res., 37, 1257-1276, doi: 10.1029/2000WR900328, 2001.

Twarakavi, N. K. C., Šimůnek, J., and Schaap, M. G.: Can texture-based classification optimally classify soils with respect to soil hydraulics? Water Resour. Res., 46, W01501, doi: 10.1029/2009WR007939, 2010.

van Genuchten, M. Th.: A closed-form equation for predicting the hydraulic conductivity for unsaturated soils, Soil Sci. Soc. Am. J., 44, 892-898, 1980.

Vogel, T., van Genuchten, M. Th. and Cislerova, M.: Effect of the shape of the soil hydraulic functions near saturation on variably-saturated flow predictions, Adv. Water Resour, 24, 133-144, 2001.

Zhang, Z. F.: Soil water retention and relative permeability for conditions from oven-dry to full saturation, Vadose Zone J., 10:1299-1308, doi: 10.2136/vzj2011.0019, 2011. 


\section{S2. Fitted parameter values for the 21 soils selected from the UNSODA database}

Table S1: The fitting parameters and their values for five UNSODA (National Agricultural Library, 2017; Nemes et al., 2001) parameterizations for clayey soils. The three-character parameterization label is explained in the main text. The soils are presented in the order of presentation of Fig. S1.

\begin{tabular}{|c|c|c|c|c|c|c|c|c|}
\hline & & & \multicolumn{6}{|c|}{$\begin{array}{l}\text { Soil (UNSODA identifier and classification according to Twarakavi et } \\
\qquad \text { al. (2010)) }\end{array}$} \\
\hline & & & $1135 \mathrm{C} 2$ & $1182 \mathrm{C} 2$ & $1122 \mathrm{C} 4$ & $1123 \mathrm{C} 4$ & $1180 \mathrm{C} 4$ & $1181 \mathrm{C} 4$ \\
\hline \multirow[t]{2}{*}{$\begin{array}{l}\text { Paramete- } \\
\text { rization }\end{array}$} & $\begin{array}{l}\text { Parame- } \\
\text { ter }\end{array}$ & Unit & & & & & & \\
\hline & $\overline{\theta_{r}}$ & - & $4.79 \mathrm{E}-6$ & $1.10 \mathrm{E}-4$ & $3.76 \mathrm{E}-4$ & $3.01 \mathrm{E}-4$ & $1.63 \mathrm{E}-4$ & $2.33 \mathrm{E}-5$ \\
\hline \multirow[t]{4}{*}{$\mathrm{BCO}$} & $\theta_{s}$ & - & 0.420 & 0.549 & 0.362 & 0.358 & 0.497 & 0.456 \\
\hline & $h_{a e}$ & $\mathrm{~cm}$ & -106 & -0.980 & -10.0 & -10.0 & -10.9 & -5.17 \\
\hline & $\lambda$ & - & $7.81 \mathrm{E}-2$ & $4.40 \mathrm{E}-1$ & $3.37 \mathrm{E}-2$ & $2.70 \mathrm{E}-2$ & $5.63 \mathrm{E}-2$ & $5.39 \mathrm{E}-2$ \\
\hline & $\overline{\theta_{s}}$ & - & 0.420 & 0.548 & 0.360 & 0.356 & 0.495 & 0.456 \\
\hline \multirow[t]{4}{*}{ FSB } & $\theta_{a}$ & - & 0.400 & 0.306 & 0.350 & 0.340 & 0.491 & 0.348 \\
\hline & $h_{a e}$ & $\mathrm{~cm}$ & -106 & -0.229 & -5.74 & -10.0 & -8.58 & -13.2 \\
\hline & $\lambda$ & - & 0.172 & $5.63 \mathrm{E}-2$ & $6.59 \mathrm{E}-2$ & $5.70 \mathrm{E}-2$ & 100 & $8.08 \mathrm{E}-2$ \\
\hline & $\theta_{s}$ & - & 0.420 & 0.549 & 0.370 & 0.370 & 0.497 & 0.456 \\
\hline \multirow[t]{4}{*}{ RNA } & $h_{a e}$ & $\mathrm{~cm}$ & -106 & -3.62 & -9.99 & -10.0 & -0.149 & -7.63 \\
\hline & $h_{j}$ & $\mathrm{~cm}$ & -109 & -12.3 & -10.7 & -10.7 & -23.8 & -22.0 \\
\hline & $h_{d}$ & $\mathrm{~cm}$ & $-1.66 \mathrm{E} 8$ & $-1.00 \mathrm{E} 9$ & $-1.00 \mathrm{E} 9$ & $-1.00 \mathrm{E} 9$ & $-1.00 \mathrm{E} 9$ & $-1.00 \mathrm{E} 9$ \\
\hline & $\theta_{r}$ & - & $2.48 \mathrm{E}-2$ & $5.09 \mathrm{E}-5$ & 0.105 & 0.182 & $2.20 \mathrm{E}-2$ & $2.12 \mathrm{E}-6$ \\
\hline \multirow[t]{5}{*}{ VGA } & $\theta_{s}$ & - & 0.418 & 0.548 & 0.359 & 0.354 & 0.497 & 0.456 \\
\hline & $\alpha$ & $\mathrm{cm}^{-1}$ & $1.59 \mathrm{E}-3$ & 1.33 & $1.27 \mathrm{E}-2$ & $3.25 \mathrm{E}-3$ & 15.1 & 1.70 \\
\hline & $n$ & - & 1.18 & 1.05 & 1.08 & 1.16 & 1.06 & 1.05 \\
\hline & $h_{a e}$ & $\mathrm{~cm}$ & -45.6 & -0.523 & -2.97 & -9.50 & $-6.45 \mathrm{E}-2$ & -4.83 \\
\hline & $\overline{\theta_{r}}$ & - & 0.270 & $9.53 \mathrm{E}-5$ & $6.58 \mathrm{E}-4$ & 0.213 & $1.18 \mathrm{E}-5$ & $3.34 \mathrm{E}-6$ \\
\hline \multirow[t]{3}{*}{ VGN } & $\theta_{s}$ & - & 0.412 & 0.548 & 0.359 & 0.354 & 0.497 & 0.456 \\
\hline & $\alpha$ & $\mathrm{cm}^{-1}$ & $1.02 \mathrm{E}-3$ & 0.738 & $1.38 \mathrm{E}-2$ & $2.87 \mathrm{E}-3$ & 9.18 & 0.142 \\
\hline & $n$ & - & 2.57 & 1.05 & 1.05 & 1.22 & 1.06 & 1.06 \\
\hline
\end{tabular}


Table S2: The fitting parameters and their values for five parameterizations for silty soils. The three-character parameterization label is explained in the main text. The soils are presented in the order of presentation of Fig. S1.

Soil (UNSODA identifier and classification according to Twarakavi et al. (2010))

\begin{tabular}{llllll}
\hline $3260 \mathrm{~B} 2$ & $3261 \mathrm{~B} 2$ & $3263 \mathrm{~B} 2$ & $3250 \mathrm{~B} 4$ & $3251 \mathrm{~B} 4$ & $4450 \mathrm{~B} 4$
\end{tabular}

\begin{tabular}{|c|c|c|c|c|c|c|c|c|}
\hline $\begin{array}{l}\text { Paramete- } \\
\text { rization }\end{array}$ & $\begin{array}{l}\text { Parame- } \\
\text { ter }\end{array}$ & Unit & & & & & & \\
\hline & $\overline{\theta_{r}}$ & - & $5.45 \mathrm{E}-6$ & $8.42 \mathrm{E}-6$ & $2.72 \mathrm{E}-7$ & $8.12 \mathrm{E}-6$ & $2.39 \mathrm{E}-5$ & $5.36 \mathrm{E}-6$ \\
\hline \multirow[t]{4}{*}{$\mathrm{BCO}$} & $\theta_{s}$ & - & 0.470 & 0.499 & 0.460 & 0.540 & 0.500 & 0.380 \\
\hline & $h_{a e}$ & $\mathrm{~cm}$ & -28.6 & -13.5 & -28.8 & -30.5 & -18.2 & -4.82 \\
\hline & $\lambda$ & - & 0.281 & 0.256 & 0.255 & 0.182 & $9.57 \mathrm{E}-2$ & $9.50 \mathrm{E}-2$ \\
\hline & $\theta_{s}$ & - & 0.470 & 0.499 & 0.460 & 0.540 & 0.500 & 0.380 \\
\hline \multirow[t]{4}{*}{ FSB } & $\theta_{a}$ & - & $1.42 \mathrm{E}-5$ & $6.90 \mathrm{E}-5$ & $1.01 \mathrm{E}-5$ & 0.173 & 0.431 & 0.320 \\
\hline & $h_{a e}$ & $\mathrm{~cm}$ & -28.6 & -13.5 & -28.8 & -30.0 & -10.9 & -0.888 \\
\hline & $\lambda$ & - & 0.281 & 0.256 & 0.255 & 0.242 & 0.197 & 0.196 \\
\hline & $\theta_{s}$ & - & 0.470 & 0.499 & 0.460 & 0.540 & 0.500 & 0.380 \\
\hline \multirow[t]{4}{*}{ RNA } & $h_{a e}$ & $\mathrm{~cm}$ & -28.6 & -13.5 & -28.8 & -30.5 & -18.2 & -4.81 \\
\hline & $h_{j}$ & $\mathrm{~cm}$ & $-8.05 \mathrm{E} 4$ & $-6.31 \mathrm{E} 4$ & $-7.76 \mathrm{E} 4$ & $-6.02 \mathrm{E} 4$ & $-2.20 \mathrm{E} 4$ & $-1.69 \mathrm{E} 4$ \\
\hline & $h_{d}$ & $\mathrm{~cm}$ & $-2.82 \mathrm{E} 6$ & $-3.14 \mathrm{E} 6$ & $-3.89 \mathrm{E} 6$ & $-1.45 \mathrm{E} 7$ & $-7.66 \mathrm{E} 8$ & $-6.23 \mathrm{E} 8$ \\
\hline & $\theta_{r}$ & - & $5.27 \mathrm{E}-2$ & $4.89 \mathrm{E}-2$ & $1.02 \mathrm{E}-3$ & $1.58 \mathrm{E}-2$ & $1.20 \mathrm{E}-4$ & $4.77 \mathrm{E}-4$ \\
\hline \multirow[t]{5}{*}{ VGA } & $\theta_{s}$ & - & 0.472 & 0.491 & 0.458 & 0.540 & 0.500 & 0.379 \\
\hline & $\alpha$ & $\mathrm{cm}^{-1}$ & $1.62 \mathrm{E}-2$ & $1.84 \mathrm{E}-2$ & $2.59 \mathrm{E}-2$ & $1.311 \mathrm{E}-2$ & $3.57 \mathrm{E}-2$ & 0.164 \\
\hline & $n$ & - & 1.47 & 1.52 & 1.30 & 1.26 & 1.11 & 1.10 \\
\hline & $h_{a e}$ & $\mathrm{~cm}$ & $-1.66 \mathrm{E}-3$ & $-2.08 \mathrm{E}-3$ & -19.2 & -5.36 & -7.11 & $-5.93 \mathrm{E}-3$ \\
\hline & $\theta_{r}$ & - & $5.27 \mathrm{E}-2$ & $4.88 \mathrm{E}-2$ & $4.52 \mathrm{E}-2$ & $3.11 \mathrm{E}-2$ & $8.93 \mathrm{E}-6$ & $8.91 \mathrm{E}-5$ \\
\hline \multirow[t]{3}{*}{ VGN } & $\theta_{s}$ & - & 0.472 & 0.491 & 0.461 & 0.540 & 0.501 & 0.379 \\
\hline & $\alpha$ & $\mathrm{cm}^{-1}$ & $1.62 \mathrm{E}-2$ & $1.84 \mathrm{E}-2$ & $1.53 \mathrm{E}-2$ & $1.21 \mathrm{E}-2$ & $2.61 \mathrm{E}-2$ & 0.164 \\
\hline & $n$ & - & 1.47 & 1.51 & 1.41 & 1.28 & 1.11 & 1.10 \\
\hline
\end{tabular}


Table S3: The fitting parameters and their values for five parameterizations for sandy soils (A3 and A4 soils according to Twarakavi et al., 2010). The three-character parameterization label is explained in the main text. The soils are presented in the order of presentation of Fig. S1.

\begin{tabular}{|c|c|c|c|c|c|c|c|c|}
\hline & & & \multicolumn{6}{|c|}{$\begin{array}{l}\text { Soil (UNSODA identifier and classification according to Twarakavi et } \\
\qquad \text { al. (2010)) }\end{array}$} \\
\hline & & & $1120 \mathrm{~A} 3$ & $1143 \mathrm{~A} 3$ & $2110 \mathrm{~A} 3$ & $2132 \mathrm{~A} 3$ & $1121 \mathrm{~A} 4$ & $1133 \mathrm{~A} 4$ \\
\hline \multirow[t]{2}{*}{$\begin{array}{l}\text { Paramete- } \\
\text { rization }\end{array}$} & $\begin{array}{l}\text { Parame- } \\
\text { ter }\end{array}$ & Unit & & & & & & \\
\hline & $\overline{\theta_{r}}$ & - & $1.77 \mathrm{E}-5$ & $4.61 \mathrm{E}-6$ & $2.31 \mathrm{E}-2$ & $5.43 \mathrm{E}-5$ & $2.72 \mathrm{E}-5$ & $1.02 \mathrm{E}-4$ \\
\hline \multirow[t]{4}{*}{$\mathrm{BCO}$} & $\theta_{s}$ & - & 0.311 & 0.279 & 0.360 & 0.303 & 0.350 & 0.330 \\
\hline & $h_{a e}$ & $\mathrm{~cm}$ & -10.0 & -7.00 & -18.5 & -8.00 & -10.0 & -206 \\
\hline & $\lambda$ & - & 0.204 & 0.168 & 0.305 & 0.107 & 0.117 & 0.102 \\
\hline & $\theta_{s}$ & - & 0.311 & 0.279 & 0.360 & 0.308 & 0.346 & 0.330 \\
\hline \multirow[t]{4}{*}{ FSB } & $\theta_{a}$ & - & $5.27 \mathrm{E}-5$ & $1.95 \mathrm{E}-4$ & $7.30 \mathrm{E}-2$ & 0.298 & 0.324 & 0.310 \\
\hline & $h_{a e}$ & $\mathrm{~cm}$ & -10.0 & -7.00 & -18.4 & -3.24 & -10.0 & -206 \\
\hline & $\lambda$ & - & 0.204 & 0.169 & 0.342 & 0.422 & 0.377 & 0.216 \\
\hline & $\theta_{s}$ & - & 0.311 & 0.279 & 0.360 & 0.303 & 0.350 & 0.330 \\
\hline \multirow[t]{4}{*}{ RNA } & $h_{a e}$ & $\mathrm{~cm}$ & -10.0 & -7.00 & -18.0 & -8.00 & -10.0 & -220 \\
\hline & $h_{j}$ & $\mathrm{~cm}$ & $-8.09 \mathrm{E} 4$ & $-7.59 \mathrm{E} 4$ & $-9.83 \mathrm{E} 4$ & $-3.90 \mathrm{E} 4$ & $-7.26 \mathrm{E} 4$ & $-6.22 \mathrm{E} 4$ \\
\hline & $h_{d}$ & $\mathrm{~cm}$ & $-1.10 \mathrm{E} 7$ & $-2.86 \mathrm{E} 7$ & $-3.78 \mathrm{E} 6$ & $-4.37 \mathrm{E} 8$ & $-3.53 \mathrm{E} 8$ & $-7.96 \mathrm{E} 8$ \\
\hline & $\theta_{r}$ & - & $7.21 \mathrm{E}-2$ & $9.77 \mathrm{E}-2$ & 0.126 & $1.26 \mathrm{E}-4$ & $5.20 \mathrm{E}-5$ & 0.201 \\
\hline \multirow[t]{5}{*}{ VGA } & $\theta_{s}$ & - & 0.305 & 0.278 & 0.360 & 0.306 & 0.339 & 0.324 \\
\hline & $\alpha$ & $\mathrm{cm}^{-1}$ & $1.72 \mathrm{E}-2$ & $4.54 \mathrm{E}-2$ & $2.63 \mathrm{E}-2$ & $6.10 \mathrm{E}-2$ & $7.22 \mathrm{E}-3$ & $7.34 \mathrm{E}-4$ \\
\hline & $n$ & - & 1.69 & 1.52 & 1.84 & 1.14 & 1.27 & 2.99 \\
\hline & $h_{a e}$ & $\mathrm{~cm}$ & $-3.81 \mathrm{E}-2$ & $-6.43 E-3$ & $-1.35 \mathrm{E}-2$ & $-3.32 \mathrm{E}-3$ & $-5.00 \mathrm{E}-2$ & -25.8 \\
\hline & $\theta_{r}$ & - & $7.21 \mathrm{E}-2$ & $9.16 \mathrm{E}-2$ & 0.126 & $2.02 \mathrm{E}-2$ & $4.19 \mathrm{E}-5$ & 0.201 \\
\hline \multirow[t]{3}{*}{ VGN } & $\theta_{s}$ & - & 0.304 & 0.278 & 0.360 & 0.305 & 0.339 & 0.324 \\
\hline & $\alpha$ & $\mathrm{cm}^{-1}$ & $1.72 \mathrm{E}-2$ & $4.71 \mathrm{E}-2$ & $2.63 \mathrm{E}-2$ & $5.46 \mathrm{E}-2$ & $7.15 \mathrm{E}-3$ & $7.34 \mathrm{E}-4$ \\
\hline & $n$ & - & 1.69 & 1.48 & 1.84 & 1.16 & 1.26 & 3.02 \\
\hline
\end{tabular}


Table S4: The fitting parameters and their values for five parameterizations for sandy soils (A1 and A2 soils according to Twarakavi et al., 2010) . The three-character parameterization label is explained in the main text. The soils are presented in the order of presentation of Fig. S1.

\begin{tabular}{|c|c|c|c|c|c|}
\hline & & & \multicolumn{3}{|c|}{$\begin{array}{l}\text { Soil (UNSODA identifier and classification according to Twarakavi } \\
\qquad \text { et al. (2010)) }\end{array}$} \\
\hline & & & $2126 \mathrm{~A} 1$ & $1142 \mathrm{~A} 2$ & 2104 A2 \\
\hline \multirow[t]{2}{*}{$\begin{array}{l}\text { Paramete- } \\
\text { rization }\end{array}$} & $\begin{array}{l}\text { Parame- } \\
\text { ter }\end{array}$ & Unit & & & \\
\hline & $\overline{\theta_{r}}$ & - & $1.63 \mathrm{E}-2$ & $9.36 \mathrm{E}-5$ & $2.27 \mathrm{E}-2$ \\
\hline \multirow[t]{4}{*}{$\mathrm{BCO}$} & $\theta_{s}$ & - & 0.377 & 0.250 & 0.398 \\
\hline & $h_{a e}$ & $\mathrm{~cm}$ & -6.78 & -7.00 & -6.79 \\
\hline & $\lambda$ & - & 0.846 & 0.211 & 0.434 \\
\hline & $\theta_{s}$ & - & 0.377 & 0.250 & 0.398 \\
\hline \multirow[t]{4}{*}{ FSB } & $\theta_{a}$ & - & $2.59 \mathrm{E}-2$ & $2.96 \mathrm{E}-4$ & $5.46 \mathrm{E}-2$ \\
\hline & $h_{a e}$ & $\mathrm{~cm}$ & -6.76 & -7.00 & -6.73 \\
\hline & $\lambda$ & - & 0.862 & 0.210 & 0.468 \\
\hline & $\theta_{s}$ & - & 0.378 & 0.250 & 0.398 \\
\hline \multirow[t]{4}{*}{ RNA } & $h_{a e}$ & $\mathrm{~cm}$ & -6.37 & -7.00 & -6.17 \\
\hline & $h_{j}$ & $\mathrm{~cm}$ & $-9.08 \mathrm{E} 4$ & $-8.17 \mathrm{E} 4$ & $-7.52 \mathrm{E} 4$ \\
\hline & $h_{d}$ & $\mathrm{~cm}$ & $-3.68 \mathrm{E} 5$ & $-9.45 \mathrm{E} 6$ & $-1.13 \mathrm{E} 6$ \\
\hline & $\theta_{r}$ & - & $3.39 \mathrm{E}-2$ & $9.64 \mathrm{E}-2$ & $3.42 \mathrm{E}-2$ \\
\hline \multirow[t]{5}{*}{ VGA } & $\theta_{s}$ & - & 0.376 & 0.242 & 0.398 \\
\hline & $\alpha$ & $\mathrm{cm}^{-1}$ & $6.84 \mathrm{E}-2$ & $1.98 \mathrm{E}-2$ & $6.97 \mathrm{E}-2$ \\
\hline & $n$ & - & 2.73 & 3.05 & 1.64 \\
\hline & $h_{a e}$ & $\mathrm{~cm}$ & $-3.49 \mathrm{E}-2$ & -0.246 & $-1.62 \mathrm{E}-2$ \\
\hline & $\theta_{r}$ & - & $3.39 \mathrm{E}-2$ & $9.42 \mathrm{E}-2$ & $3.41 \mathrm{E}-2$ \\
\hline \multirow[t]{3}{*}{ VGN } & $\theta_{s}$ & - & 0.376 & 0.242 & 0.398 \\
\hline & $\alpha$ & $\mathrm{cm}^{-1}$ & $6.84 \mathrm{E}-2$ & $1.98 \mathrm{E}-2$ & $6.97 \mathrm{E}-2$ \\
\hline & $n$ & - & 2.73 & 2.93 & 1.64 \\
\hline
\end{tabular}


S3. Root means square errors of the parameter fits for the 21 soils selected from the UNSODA database

475 Table S5. Root mean square errors of the parameter fits for the clayey soils.

\begin{tabular}{lllllll}
\hline & \multicolumn{5}{c}{ Soil (UNSODA identifier and classification according to Twarakavi et al. (2010)) } \\
\cline { 2 - 7 } Parameterization & $1135 \mathrm{C} 2$ & $1182 \mathrm{C} 2$ & $1122 \mathrm{C} 4$ & $1123 \mathrm{C} 4$ & $1180 \mathrm{C} 4$ & $1181 \mathrm{C} 4$ \\
\hline BCO & 0.0913 & 0.0494 & 0.0349 & 0.0489 & 0.0187 & 0.0428 \\
FSB & 0.0721 & 0.0441 & 0.0212 & 0.0320 & 0.1196 & 0.0360 \\
RNA & 0.0812 & 0.0913 & 0.1235 & 0.1501 & 0.0347 & 0.0570 \\
VGA & 0.0487 & 0.0485 & 0.0204 & 0.0243 & 0.0192 & 0.0429 \\
VGN & 0.0208 & 0.0488 & 0.0197 & 0.0244 & 0.0194 & 0.0433 \\
\hline
\end{tabular}


Table S6. Root mean square errors of the parameter fits for the silty soils.

\begin{tabular}{lllllll}
\hline & \multicolumn{5}{c}{ Soil (UNSODA identifier and classification according to Twarakavi et al. (2010)) } \\
\cline { 2 - 7 } Parameterization & $3260 \mathrm{~B} 2$ & $3261 \mathrm{~B} 2$ & $3263 \mathrm{~B} 2$ & $3250 \mathrm{~B} 4$ & $3251 \mathrm{~B} 4$ & $4450 \mathrm{~B} 4$ \\
\hline BCO & 0.0793 & 0.1316 & 0.0973 & 0.0822 & 0.0551 & 0.0499 \\
FSB & 0.0794 & 0.1316 & 0.0973 & 0.0815 & 0.0395 & 0.0445 \\
RNA & 0.0793 & 0.1316 & 0.0973 & 0.0822 & 0.0551 & 0.0499 \\
VGA & 0.0455 & 0.0607 & 0.0818 & 0.0413 & 0.0466 & 0.0485 \\
480 & 0.0455 & 0.0607 & 0.0638 & 0.0413 & 0.0474 & 0.0485 \\
\hline
\end{tabular}


Table S7. Root mean square errors of the parameter fits for the sandy soils (A3 and A4 soils according to Twarakavi et al., 2010)

\begin{tabular}{lllllll}
\hline & \multicolumn{5}{l}{ Soil (UNSODA identifier and classification according to Twarakavi et al. (2010)) } \\
\cline { 2 - 7 } Parameterization & $1120 \mathrm{~A} 3$ & $1143 \mathrm{~A} 3$ & $2110 \mathrm{~A} 3$ & $2132 \mathrm{~A} 3$ & $1121 \mathrm{~A} 4$ & $1133 \mathrm{~A} 4$ \\
\hline BCO & 0.0926 & 0.0501 & 0.0507 & 0.0356 & 0.1288 & 0.0803 \\
FSB & 0.0926 & 0.0500 & 0.0507 & 0.0292 & 0.1054 & 0.0700 \\
RNA & 0.0926 & 0.0500 & 0.0507 & 0.0356 & 0.1288 & 0.0775 \\
VGA & 0.0446 & 0.0334 & 0.0377 & 0.0203 & 0.0720 & 0.0175 \\
VGN & 0.0446 & 0.0334 & 0.0377 & 0.0207 & 0.0720 & 0.0175 \\
\hline
\end{tabular}


Table S8. Root mean square errors of the parameter fits for the sandy soils (A1 and A2 soils according to Twarakavi et al., 2010)

\begin{tabular}{lllc}
\hline \multirow{2}{*}{ Parameterization } & \multicolumn{2}{l}{ Soil (UNSODA identifier and classification according to Twarakavi et al. (2010)) } \\
\cline { 2 - 4 } & $2126 \mathrm{~A} 1$ & $1142 \mathrm{~A} 2$ & $2104 \mathrm{~A} 2$ \\
\hline BCO & 0.0620 & 0.0990 & 0.0480 \\
FSB & 0.0626 & 0.0990 & 0.0517 \\
RNA & 0.0659 & 0.0989 & 0.0553 \\
VGA & 0.0330 & 0.0250 & 0.0278 \\
VGN & 0.0330 & 0.0252 & 0.0278 \\
\hline
\end{tabular}




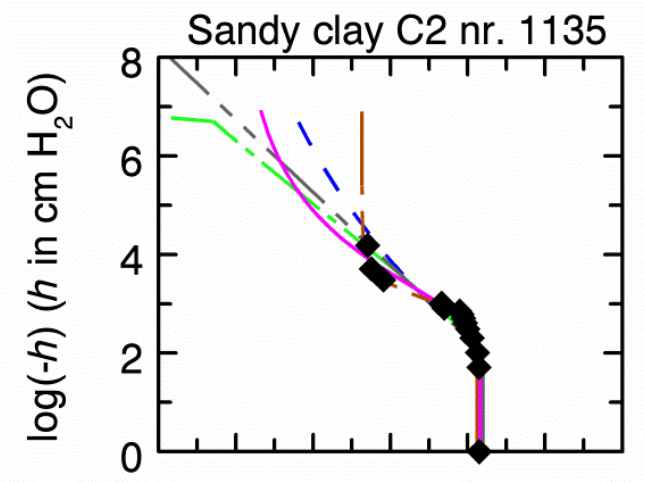

Clay C2 nr. 1182

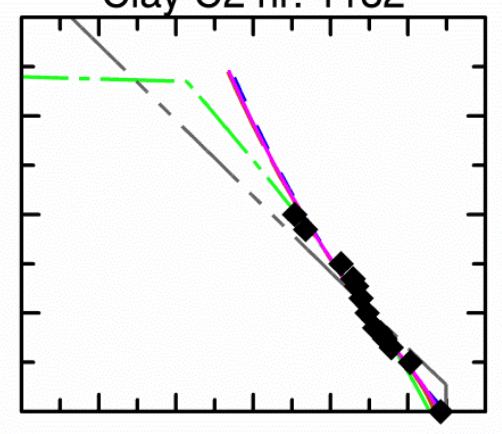

Sandy clay loam C4 nr. 1122
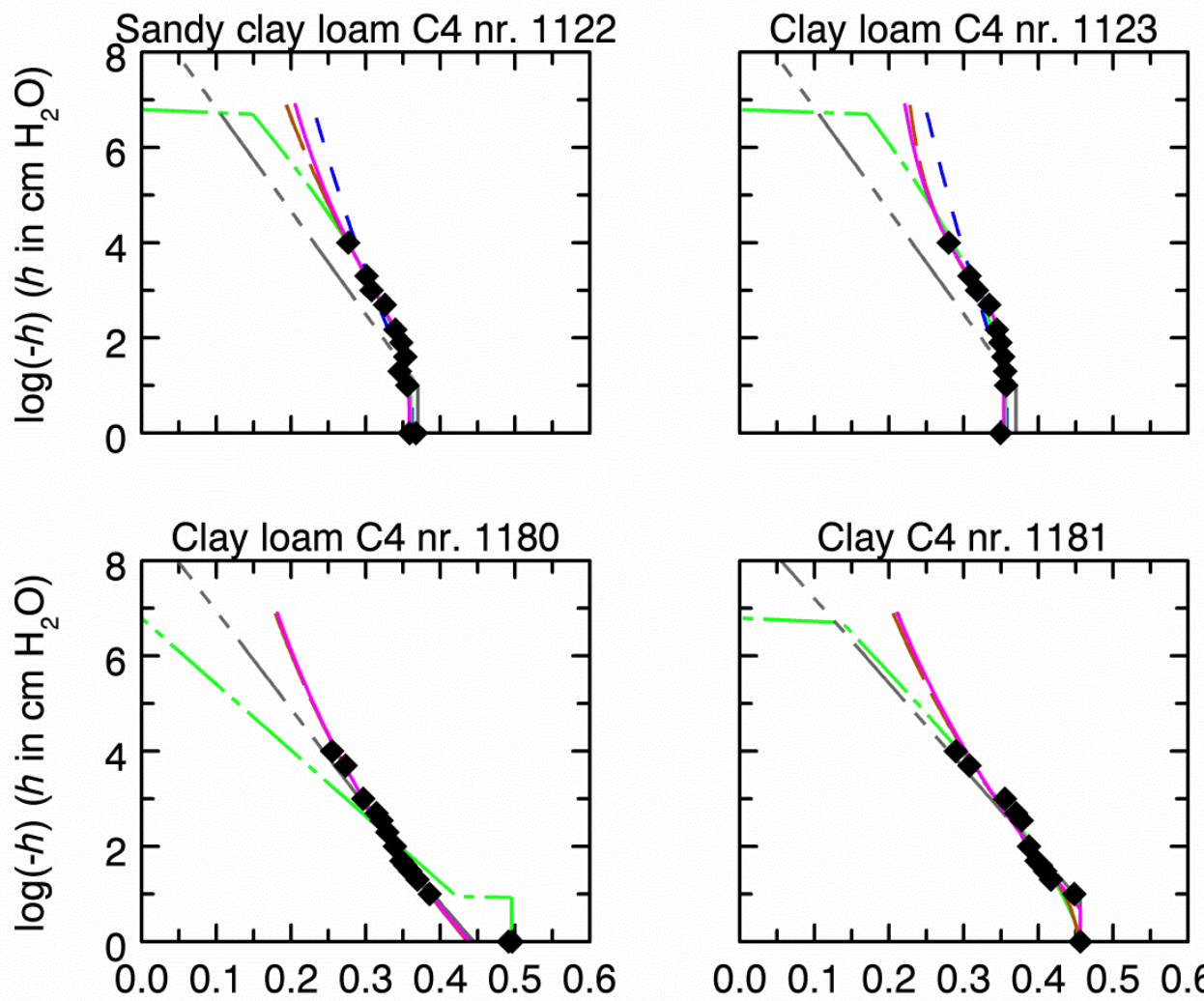

Clay C4 nr. 1181

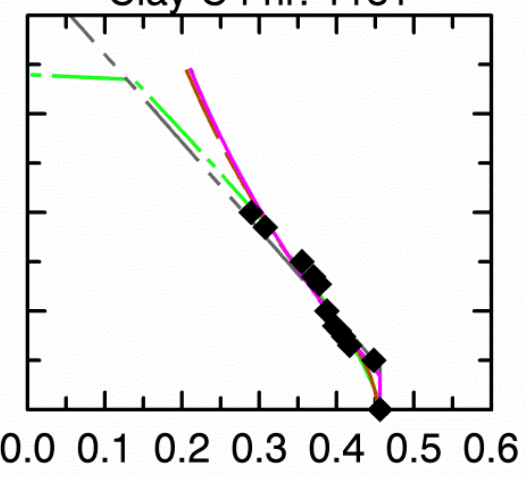

Volumetric water content

Volumetric water content

$--\mathrm{BCO}-\mathrm{FSB}-\mathrm{RNA}-\mathrm{VGN}-\mathrm{VGA} \bullet$ Data 


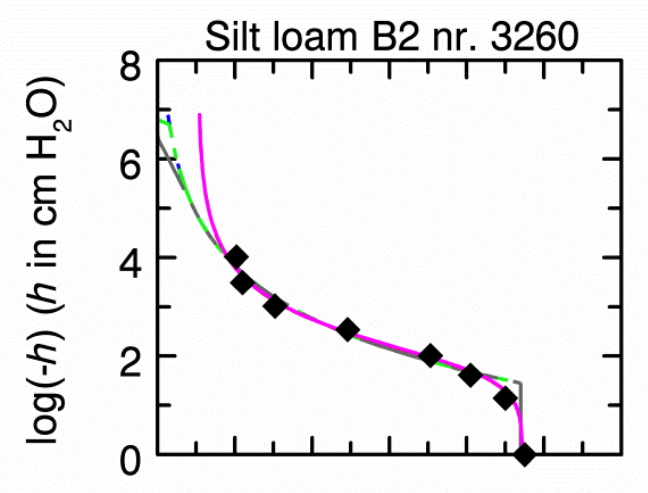

Silt loam B2 nr. 3261
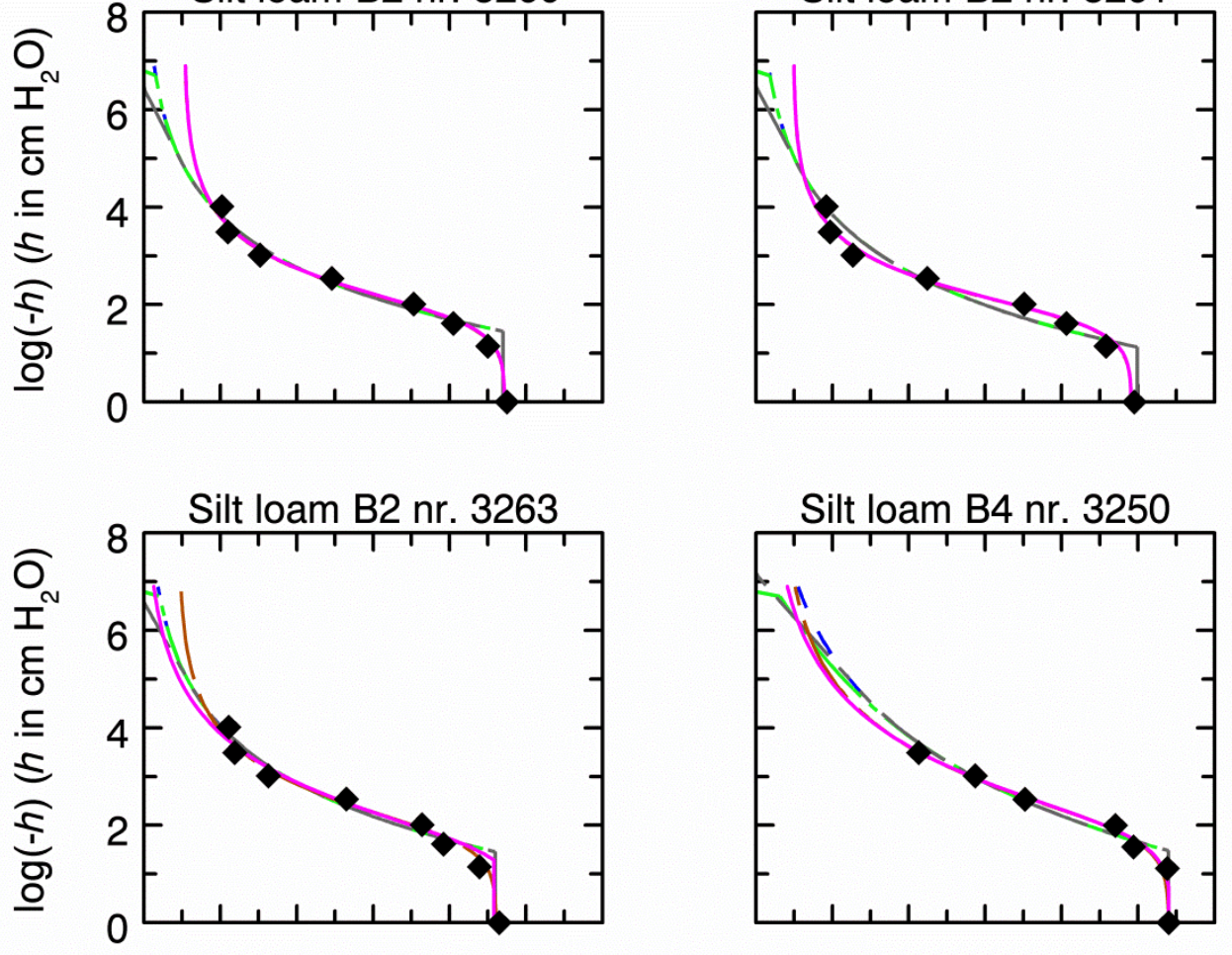

Silt loam B4 nr. 3250
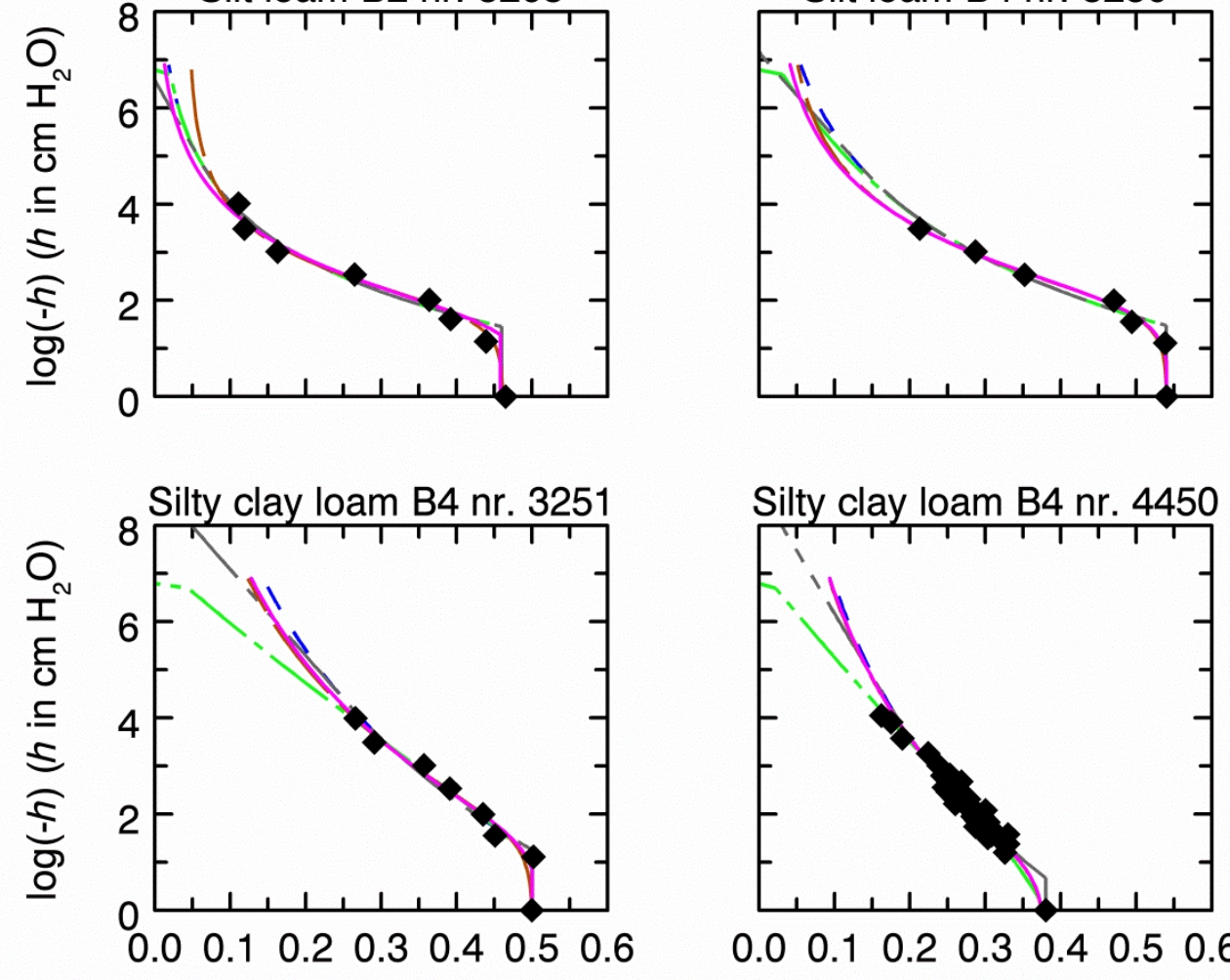

Silty clay loam B4 nr. 4450

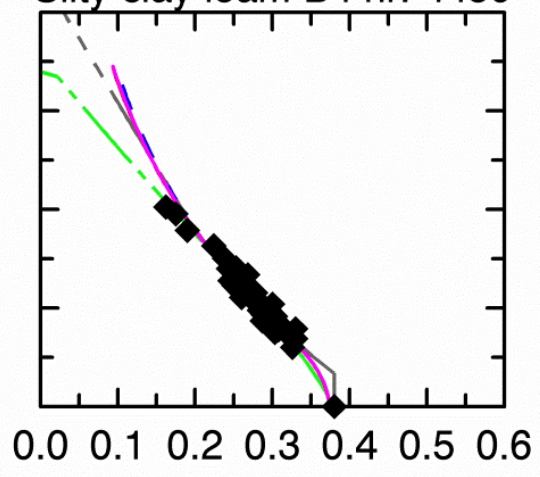

Volumetric water content

Volumetric water content

$--\mathrm{BCO}-\mathrm{FSB}-\mathrm{RNA}-\mathrm{VGN}-\mathrm{VGA} \bullet$ Data 

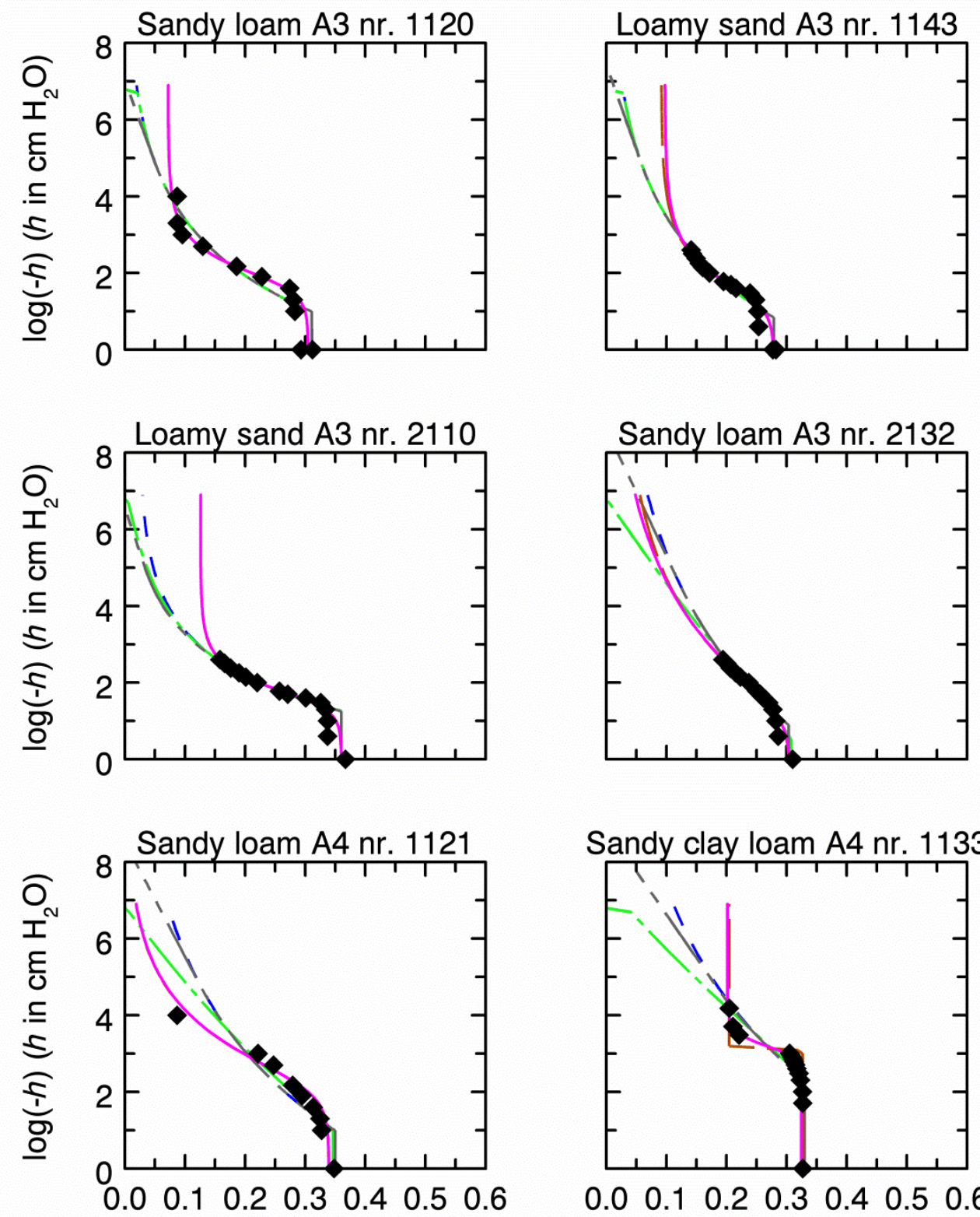

Sandy clay loam A4 nr. 1133

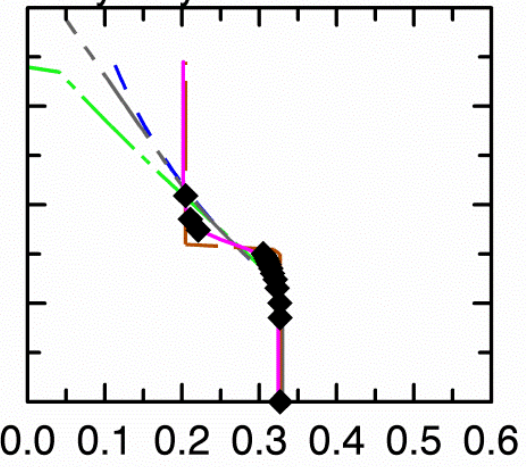

Volumetric water content

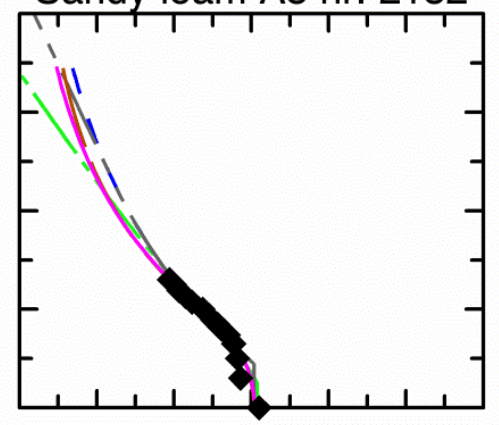

Volumetric water content

- $\mathrm{BCO}$ - FSB — RNA — VGN - VGA - Data 

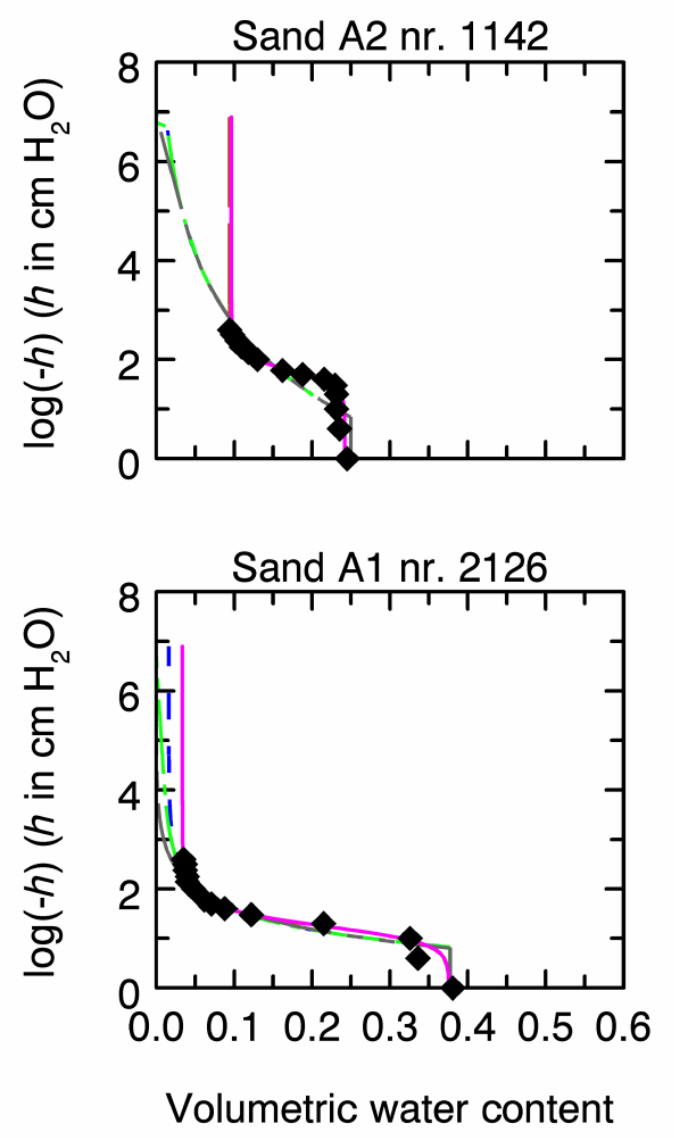

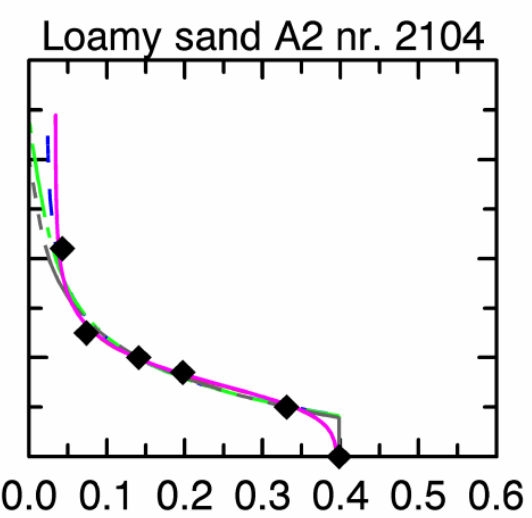

Volumetric water content

\section{$--\mathrm{BCO}-\mathrm{FSB}-\mathrm{RNA}-\mathrm{VGN}-\mathrm{VGA} \bullet$ Data}

Figure S1. Fits of five parameterizations to data from 21 soils selected from the UNSODA database. The soils are characterized by their USDA texture classification and Twarakavi et al.'s (2010) classification, and identified by the four-digit number in the UNSODA database. The parameterizations are those of Brooks and Corey (1964) (BCO), Fayer and Simmons (1995) with the capillary bound water content forced to zero when the adsorbed water content reaches zero (FSB), Rossi and Nimmo (1994), but with a non-zero air-entry value (RNA), van Genuchten (1980) (VGN), and Ippisch et al. (2006) (VGA). Note that the vertical variation of the water content in samples at hydrostatic equilibrium was accounted for during the fitting process. The data in the wet range may therefore give a smoother representation than the underlying retention curve (Liu and Dane, 1995). N.B. Data points obtained at zero matric potential are plotted for $\mathrm{pF}=0$ (corresponding to $h=-1 \mathrm{~cm}$ ). 